\title{
QUEEN'S
UNIVERSITY
BELFAST
}

\section{Mode I intralaminar fracture toughness of 2D woven carbon fibre reinforced composites: A comparison of stable and unstable crack propagation techniques}

Dalli, D., Falzon, B., Catalanotti, G., Varandas, L., \& Foster, S. (2019). Mode I intralaminar fracture toughness of 2D woven carbon fibre reinforced composites: A comparison of stable and unstable crack propagation techniques. Engineering Fracture Mechanics. https://doi.org/10.1016/j.engfracmech.2019.04.003

\section{Published in:}

Engineering Fracture Mechanics

\section{Document Version:}

Peer reviewed version

Queen's University Belfast - Research Portal:

Link to publication record in Queen's University Belfast Research Portal

\section{Publisher rights}

Copyright 2019 Elsevier.

This manuscript is distributed under a Creative Commons Attribution-NonCommercial-NoDerivs License

(https://creativecommons.org/licenses/by-nc-nd/4.0/), which permits distribution and reproduction for non-commercial purposes, provided the author and source are cited

\section{General rights}

Copyright for the publications made accessible via the Queen's University Belfast Research Portal is retained by the author(s) and / or other copyright owners and it is a condition of accessing these publications that users recognise and abide by the legal requirements associated with these rights.

Take down policy

The Research Portal is Queen's institutional repository that provides access to Queen's research output. Every effort has been made to ensure that content in the Research Portal does not infringe any person's rights, or applicable UK laws. If you discover content in the

Research Portal that you believe breaches copyright or violates any law, please contact openaccess@qub.ac.uk. 


\title{
Mode I intralaminar fracture toughness of 2D woven carbon fibre reinforced composites: A comparison of stable and unstable crack propagation techniques
}

\author{
D. Dalli ${ }^{1}$, G. Catalanotti ${ }^{1 *}$, L. F. Varandas ${ }^{1}$, B. G. Falzon ${ }^{1 *}$, S. Foster $^{2}$ \\ ${ }^{1}$ Advanced Composites Research Group (ACRG), School of Mechanical and Aerospace Engineering, Queen's \\ University Belfast, Ashby Building, Stranmillis Road, Belfast BT9 5AH, UK. \\ ${ }^{2}$ McLaren Racing Limited, McLaren Technology Centre, Chertsey Road, Woking, Surrey, GU21 4YH, UK.
}

\begin{abstract}
This paper presents an experimental and numerical comparison of stable and unstable crack propagation techniques used to measure the mode I intralaminar fracture toughness of 2D woven carbon fibre composites. Compact Tension (CT) and Double Edge Notch Tension (DENT) specimens are used for the stable and unstable experimental tests, respectively. The precrack tip radius sensitivity of the scaled DENT specimens is investigated, concluding that the tested tip radii do not substantially affect the measured fracture toughness. The fracture toughness data obtained from the DENT and CT specimens are found to be in good agreement for both tested materials.
\end{abstract}

Keywords: Mode I intralaminar fracture toughness, (A) Carbon fibre, (C) Analytical modelling, (C) Computational modelling, (D) Mechanical testing

\footnotetext{
* Corresponding authors.

E-mail address: G.Catalanotti@qub.ac.uk (G.Catalanotti), B.Falzon@qub.ac.uk (B.G.Falzon).
} 


\section{Nomenclature}

$a, a_{e f f}, a_{0} \quad$ crack length, effective crack length, initial crack length value

$\bar{A}, \bar{C} \quad$ fitting parameters for linear regression I

Á, $\quad$ fitting parameters for linear regression II

$c_{f} \quad$ critical crack extension for an infinite specimen

C specimen compliance

CV\% Coefficient of Variation percentage

$\operatorname{det} \boldsymbol{F} \quad$ determinant of the deformation gradient

$d_{11 T(C)}^{T} \quad$ longitudinal tensile / compressive damage variable for the tows

$d^{m} \quad$ matrix damage variable

$E_{11}, E_{22} \quad$ in-plane elastic modulus in the warp direction, and in the weft direction of the weave

$E_{11}^{T}, E_{22}^{T} \quad$ in-plane elastic moduli of the tows: longitudinal and transverse

$E_{33}^{T} \quad$ through-thickness elastic modulus of the tows

$E_{11}^{*} \quad$ normalised elastic modulus in the warp direction, with respect to the equivalent modulus

$E^{m} \quad$ elastic modulus of the epoxy matrix

$E^{\quad} \quad$ equivalent modulus

$f(a) \quad$ normalised energy release rate correction factor

$G_{12} \quad$ in-plane shear modulus of the weave

$G_{12}^{T} \quad$ in-plane shear modulus of the tows

$G_{I}, G_{I c} \quad$ mode I energy release rate, and its critical value

$G_{C C}^{1 T}, G_{I c}^{1 T} \quad$ compressive and tensile longitudinal mode I intralaminar fracture toughness of the fibre tows

$G_{C c}^{2 T}, G_{I c}^{2 T} \quad$ compressive and tensile transverse mode I intralaminar fracture toughness of the fibre tows

$G_{I I C}^{12 T}, G_{I I C}^{13 T}, G_{I I C}^{23 T}$ in-plane and through thickness mode II intralaminar fracture toughness of the fibre tows

$G_{I c}^{m} \quad$ mode I fracture toughness of the epoxy matrix

$K_{I}, K_{I c} \quad$ stress intensity factor, and its critical value

$l \quad$ half length of the Double Edge Notch Tension specimen

$l_{f p z} \quad$ length of a fully-developed fracture process zone

$l_{i j} \quad$ element size

$L_{E C} \quad$ length of the Embedded Cell

$M, N \quad$ fitting parameters for bilogarithmic regression

$P, P_{1}, P_{2} \quad$ load, and peak load values

$P_{c} \quad$ critical load value

$r_{0} \quad$ initial precrack tip radius 
$R$

$R_{S S}$

$S_{12}^{T}, S_{13}^{T}, S_{23}^{T}$

SD

$t$

$\operatorname{tr}(Q)$

$u_{1}, u_{2}$

$u_{j}$

$u_{y}, \dot{u}_{y}$

$v_{12}, v_{21}$

$v_{12}^{T}$

$v_{13}, v_{23}$

$v_{13}^{T}, v_{23}^{T}$

$v^{m}$

$V, V_{0}$

w

$W_{\text {tow }}$

$W_{E C}$

$x_{1}, x_{2}$

$X_{C}^{T}, X_{T}^{T}$

$X_{C}^{m}, X_{T}^{m}$

$Y_{C}^{T}, Y_{T}^{T}$

$Z_{i}$

$\Delta a$

$\alpha, \alpha_{0}$

$\alpha_{f}, \beta_{f}, \chi$

$\kappa$

$\kappa_{0}, \kappa_{0}$

$\lambda$

$\eta$

$\rho$

$\sigma$

$\sigma_{u}$

crack growth resistance

steady-state fracture toughness

in-plane and through-thickness shear strengths of the tows

Standard Deviation

specimen thickness

trace of the stiffness matrix

displacements at corresponding peak loads

nodal displacement

vertical nodal displacement and velocity

in-plane major and minor Poisson's ratio of the weave

in-plane Poisson's ratio of the tows

through-thickness Poisson's ratio of the weave

through-thickness Poisson's ratio of the tows

Poisson's ratio of the epoxy matrx

deformed and undeformed volumes of the element

characteristic size of the Double Edge Notch Tension specimen, half the specimen width

width of the finite element model tows

width of the embedded cell

in-plane tow axes of the weave: warp, and weft directions

compressive and tensile longitudinal strengths of the tows

compressive and tensile strengths of the epoxy matrix

compressive and tensile transverse strengths of the tows

nodal load

crack length increment

shape parameter, and its initial value

fitting parameters for the compliance function

geometric correction factor

geometric correction factor value at $\alpha=\alpha_{0}$, and its derivative with respect to $\alpha$

dimensionless elastic parameter for material orthotropy

material softening parameter

dimensionless elastic parameter for material orthotropy

nominal stress

peak nominal stress 
shape parameter 


\section{Introduction}

The mode I intralaminar fracture toughness of carbon fibre reinforced polymer (CFRP) composites has been the subject of extensive investigations [1,2]. However, none of the proposed techniques have been standardised, unlike the procedures developed for testing elastic, strength (e.g. [3]) and most interlaminar fracture toughness properties (e.g. [4]). Recently developed Finite Fracture Mechanics (FFM) and continuum damage models require the input of either a steady-state fracture toughness, $R_{s S}$, or a softening law derived from the material's crack resistance curve ( $R$-curve), to accurately capture the progressive damage in composites [511]. The automotive and aerospace industries are still reluctant to adopt the use of such material damage models, partly due to the aforementioned lack of standardised experimental methods for determining the various intralaminar fracture toughness values.

The available literature on mode I intralaminar fracture toughness can be grouped into stable and unstable crack propagation techniques. Each comprise different test specimens and data reduction methods, with their own respective advantages and draw-backs.

Stable crack propagation techniques have been more extensively studied. Several different specimen geometries have been tested, for an assortment of unidirectional (UD) and bi-dimensional (2D) woven composites [12-14], most notably for Compact Tension (CT) tests. Other geometries have also been tested, including the 4-Point-Bend (4PB) with a single edge notch [15], and Over-height Compact Tension (OCT) [16]. Furthermore, numerous data reduction techniques have been developed for obtaining the fracture toughness from these stable crack propagation experiments. The CT geometry remains by far the most used and well documented specimen type. The extensive work conducted on CT specimens has necessitated variant design modifications, such as the doubly-tapered CT (2TCT) by Blanco et. al. [14], aimed at supressing the onset of premature failures observed in the standard CT geometry (back-end compressive failure; failure at the load introduction points; and buckling). These stable crack propagation experiments require the measurement of the crack propagation, usually by tracking the crack tip location, which complicates the execution of the experiment.

More recently, unstable crack propagation techniques have been developed, which take advantage of the quasibrittle nature of these composites. Using Bažant's size effect method [17], the fracture toughness is obtained by testing geometrically scaled specimens such as Single/Double Edge Notch Tension (SENT/DENT) specimens $[2,18]$. These techniques enable the construction of a size-independent $R$-curve. The same cannot be ascertained for single-size stable propagation geometries such as the CT, without first testing larger versions of such specimens to ensure this steady-state value is actually size independent [2]. These unstable size effect methodologies have also been employed in the measurement of the mode II [19] and compressive [20] intralaminar fracture toughness properties. Recent advances in measuring the dynamic intralaminar fracture toughness of CFRPs have also made use of such methods, including testing in mode I tension [21] and compression [22]. 
One of the major drawbacks of both stable and unstable crack propagation specimens is in the manufacturing of precracks [15]. The preferred method of introducing a thin precrack in CFRP specimens is by using a razor blade, or using a diamond-coated thread wire [23], usually achieving a tip radius of around 0.1 $0.2 \mathrm{~mm}$. This task is difficult to perform accurately and repeatedly. Experimental errors can arise when precracks are misaligned, curved, or of incorrect length. This is a deterrent to industrial-level testing, where the number of specimens required can be significant. A simpler automated precrack introduction technique would be preferred for the standardisation of such experiments, such as using Computer Numerical Control (CNC) milling, to achieve improved geometrical tolerances and faster production if the slightly larger tip radii can be tolerated.

Considering precrack tip radii in the range $0.015 \mathrm{~mm}$ to $0.75 \mathrm{~mm}$, it has already been shown that a precrack tip radius sensitivity exists when measuring the initiation fracture toughness of unidirectional composites using stably propagating CT specimens, while the steady-state fracture toughness is unaffected [24]. This initial sensitivity is a result of the machined precrack tip radius from which the crack starts to propagate. The steadystate fracture toughness of such specimens is determined using sets of experimental points which are located through measurements recorded when the crack has propagated some distance away from the initial crack tip such that the precrack tip radius is not influential.

Unstable specimen testing of 2D woven SENT specimens, conducted by Salviato et al. [18], made use of sharp precracks similar to CT specimens, with a tip radius 70 times smaller than the material's Representative Unit Cell (RUC). No justification was given as to whether such a precrack radius would be sufficiently small for unstable propagation tests. Catalanotti et al. [2] claimed a certain amount of precrack tip radius insensitivity for unstable specimens (both UD and 2D woven), testing DENT specimens with milled precracks of $0.5 \mathrm{~mm}$ tip radius while assuming a slit crack (tip radius of 0 ) in the numerical derivation of the geometrical correction factor. This claim was based on the assumption that the peak load instability occurs after the crack has already propagated to its critical length, making it a sharp crack tip at failure. This claim was only experimentally substantiated by previous testing of a single UD cross-ply centre cracked specimen [25], tested with a precrack radius of $0.2 \mathrm{~mm}$. A similar peak load had been observed for similar specimens with blunt precrack radii of 0.5 $\mathrm{mm}$. Understanding this sensitivity for unstable testing is even more crucial, since the steady-state fracture toughness is derived from the peak loads observed for the different sized specimens. Thus, the existence of a peak load sensitivity on the precrack tip radius may result in an inaccurate measurement of the entire $R$-curve.

This work compares the mode I intralaminar fracture toughness obtained by stable (CT) and unstable (DENT) crack propagation testing of two woven CFRP composites. Analytical models reported in literature are briefly presented for both techniques, and subsequently used in the data reduction of the DENT and CT experimental results $[2,26]$. Two numerical studies are performed to assess the effect of precrack tip radius on the fracture toughness results obtained from DENT testing. The first study concerns the sensitivity of the geometric correction factor used in the size effect data reduction method. By making use of appropriate 
constitutive material models, the second study compares peak loads and fracture behaviour of two DENT finite element models incorporating different precrack tip radii (same as the experimentally tested specimen radii), using an embedded cell modelling approach. A concluding discussion weighs the respective advantages and draw-backs of each method, and presents their possible applicability in industry.

\section{Data reduction techniques}

\subsection{Analytical models for the stable crack propagation of CT specimens}

The determination of the $R$-curve is achieved by studying the problem of a crack propagating in a $2 \mathrm{D}$ orthotropic body along one of its preferred axes [27]. In a balanced 2D woven laminate, where all plies have been stacked with the same orientation, the two in-plane preferred axes are the warp $\left(x_{1}\right)$ and weft $\left(x_{2}\right)$ fibre tow directions (see Figure 1a). The critical values of the mode I energy release rate, $G_{\mathrm{Ic}}^{1}$ and $G_{\mathrm{Ic}}^{2}$, are respectively associated with a crack propagating perpendicular to each of the in-plane axes, $x_{1}$ and $x_{2}$. These two values are virtually the same due to the balanced nature of the woven plies; thus, the 1 or 2 apex notation will be hereon omitted for simplicity.

Several data reduction approaches have been used to determine the mode I intralaminar fracture toughness from stable CT specimen testing. These include: (i) the area method; (ii) Compliance Calibration / Modified Compliance Calibration (CC/MCC) techniques; (iii) the Finite Element Method (FEM)-based approach; and (iv) the direct calculation of the critical value of the J-Integral, among others.

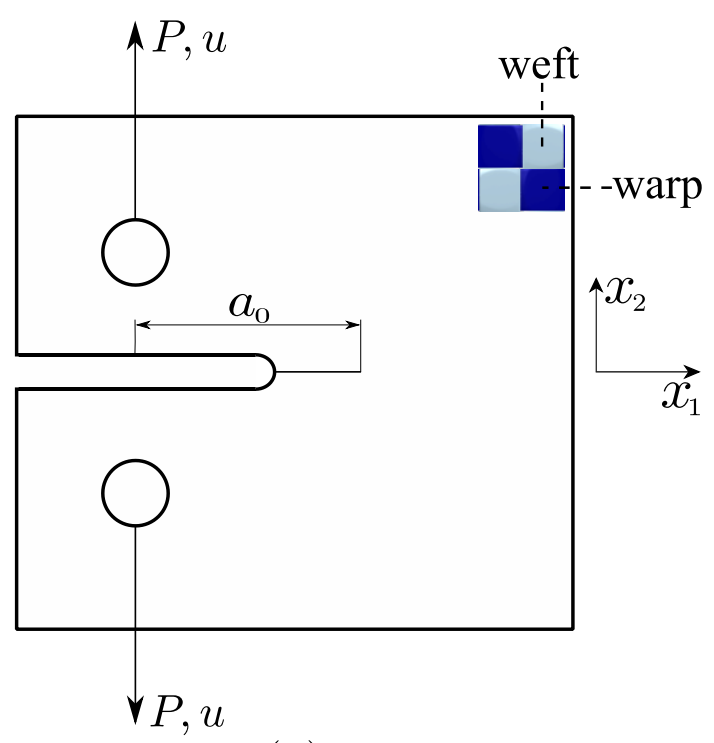

(a)

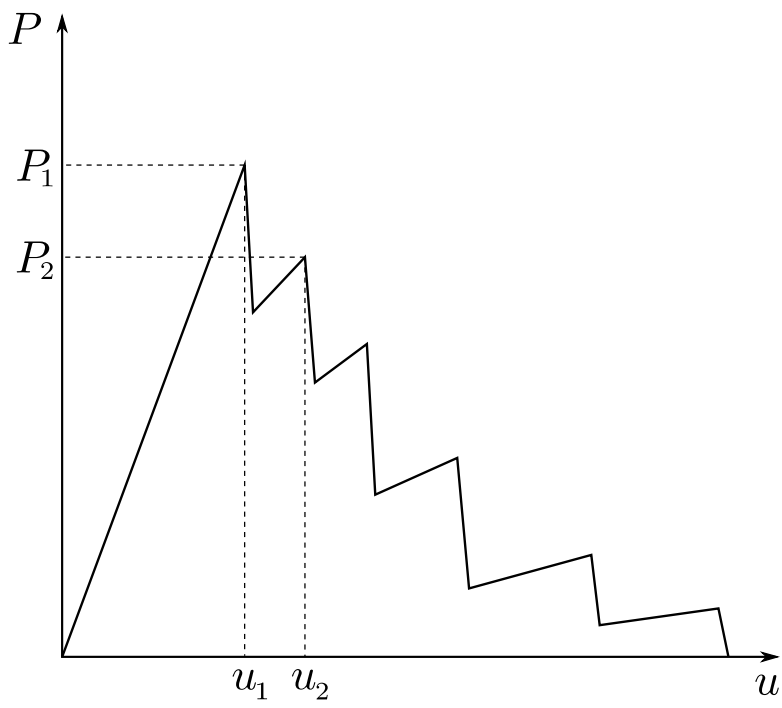

(b)

Figure 1 - Compact Tension (CT) specimen (a); typical CT experimental load-displacement curve 
(i) Area method

The area method [28] is the simplest, making use of two sets of load peaks $\left(P_{1}, P_{2}\right)$ from the loaddisplacement curve (see Figure 1b), with the corresponding loading point displacements $\left(u_{1}, u_{2}\right)$, and the crack extension between these peaks $(\Delta a)$, for a specimen of thickness, $t$ :

$$
G_{I c}=\frac{1}{2 t \Delta a}\left(P_{1} u_{2}-P_{2} u_{1}\right)
$$

(ii) Compliance Calibration techniques

CC and MCC techniques use the specimen compliance, $C$, obtained either experimentally or numerically, to calculate $G_{I C}$ as:

$$
G_{I C}=\frac{P_{c}^{2}}{2 t} \frac{d C}{d a}
$$

For CC, the compliance is measured directly from the load-displacement curve of the tested specimens. The crack length for the CC data reduction is measured optically, and is thus prone to error [26]. Catalanotti et al. [29] removed this subjectivity by developing an algorithm to be used with Digital Image Correlation (DIC) in order to locate the crack tip (implicitly assuming a self-similar crack propagation). For the MCC method, the compliance is either measured experimentally from specimens with different machined precrack lengths, or obtained numerically, through an elastic Finite Element (FE) model of a specimen with varying crack length [26,30]. A fitting function is used for this compliance, with three coefficients, $\alpha_{f}, \beta_{f}$, and $\chi$ [31]:

$$
C=\left(\alpha_{f} a-\beta_{f}\right)^{\chi}
$$

By rearranging this compliance fit, an effective crack length, $a_{e f f}$, is derived for all load peaks of the tested specimens, with $C=u / P$ :

$$
a_{e f f}=\frac{c^{1 / \chi}-\beta}{\alpha}
$$

(iii) FEM-based approach

The stress intensity factor $K_{I}$, and consequently its critical value $K_{I c}$, can be derived from empirical solutions, such as the ones used for isotropic materials [32], or for low values of orthotropy [27], and consequently the critical value of the energy release rate, $G_{I c}$, can be obtained from:

$$
G_{I C}=\frac{1}{E} K_{I C}^{2}
$$


where $E$ is the equivalent modulus. For isotropic solutions, $E=E$, the material's Young's modulus. The orthotropic solutions necessitate a different solution for $E$, which is dependent on two dimensionless parameters, $\lambda$ and $\rho$, which define the laminate's orthotropic nature. In a state of plane stress $E$ is defined as:

$$
\begin{gathered}
E=\lambda^{1 / 4} \sqrt{E_{11} E_{22}\left(\frac{2}{1+\rho}\right)} \\
\lambda=\frac{E_{22}}{E_{11}}, \quad \rho=\frac{\sqrt{E_{11} E_{22}}}{2 G_{12}}-\sqrt{v_{12} v_{21}}
\end{gathered}
$$

where $E_{11}, E_{22}$ are the elastic moduli in the weave's warp and weft directions, $G_{12}$ is the in-plane shear modulus, and $v_{12}, v_{21}$ are the in-plane Poisson's ratios.

The use of isotropic or low orthotropy solutions have been shown to provide erroneous estimates of $K_{I c}$ for highly orthotropic cross-ply or woven laminates [2,26,30], such as the ones being tested here. In this case, a possible approach is to numerically calculate the correction factor using well-known numerical techniques, such as the Virtual Crack Closure Technique (VCCT) or the domain integral method. Using the numerical model's normalised energy release rate (unit displacement per unit load) as a correction factor, $f(a)$, Laffan et al. [26] calculated the fracture toughness as:

$$
G_{I c}=\left(\frac{P_{c}}{t}\right)^{2} f(a)
$$

where the correction factor, $f(a)$, needs to be recalculated for any material system. However, this can be easily corrected by calculating $f(a)$ as a function of material orthotropy, as proposed by Ortega et al. [30].

(iv) Direct calculation of the critical value of the J-Integral

Finally, the critical value of the energy release rate can be directly measured using the field data obtained using Digital Image Correlation (DIC), as proposed by Catalanotti et al. [29]. This methodology does not require the calculation of any correction factor and uses the displacement and strain fields to obtain the real-time values of the J-integral during the test.

Due to the complications arising from specimen preparation and experimental testing setup, the aerospace and automotive industries are seeking simpler approaches to measure intralaminar fracture toughness. Furthermore, such industries may be further discouraged from adopting experimental data reduction methods which require FE modelling. The area method, although offering larger scatter in results [26], is the only technique independent of both DIC and FE tools, and is currently being used by at least one major airframe 
manufacturer. Consequently this data reduction method is used to compare stable crack propagation methods with an unstable crack propagation approach developed below.

2.2 Analytical and numerical model for the unstable crack propagation of DENT specimens (Size effect method)

The FEM-based approach and the direct calculation of the critical value of the J-Integral are also applicable to unstable data reduction schemes [25]. However, the size effect method is simpler to implement and provides a size-independent $R$-curve. The work presented here uses the size effect method as the only data reduction technique for unstable crack propagation testing.

An analytical model, based on [2], was used to obtain the fracture toughness from the unstable DENT specimen testing. Considering the specimen geometry in Figure 2 (width $2 w$, length $2 l$, and initial cracks each of length $a_{0}$ ) for a $2 \mathrm{D}$ orthotropic laminate, the mode I energy release rate, $G_{I}$, for a crack propagating perpendicular to the warp direction, $x_{1}$, of the woven composite, under tensile displacement, $u$, is [27]:

$$
G_{I}=\frac{1}{\grave{E}} K_{I}^{2}
$$

where the equivalent modulus is calculated using Eq. (6) and (7) for orthotropic materials.

The stress intensity factor for the DENT geometry can be defined in terms of a characteristic size (here chosen to be half the specimen's width), $w$, a nominal stress, $\sigma=P / 2 w t$ (where $P$ is the applied load, and $t$ is the specimen thickness), and a geometric correction factor, $\kappa$ :

$$
K_{I}=\sigma \sqrt{w} \kappa
$$

The correction factor $\kappa$ will depend on the material parameters $(\lambda$ and $\rho$ ), and on the specimens' shape parameters $(\alpha=a / w$ and $\xi=l / w)$. The specimens tested in this work were manufactured from balanced woven laminates $(\lambda=1)$. Moreover, by scaling the specimen geometry (in this case maintaining $l=3 w$ ), $\xi$ assumes a constant value, and $\kappa$ can be obtained as a function of $\alpha$ and $\rho$. Furthermore, as demonstrated by Catalanotti et al. [2], the obtained $\kappa$ can be considered valid for $\xi \geq 3$. The correction factor $\kappa$ was numerically determined by applying the Virtual Crack Closure Technique (VCCT) to a 2D quarter model of the DENT specimen (Figure 3), in the commercial FE software package Abaqus ${ }^{\circledR}$ [33]. Elastic properties were assigned to the 4-node reduced integration elements (CPS4R). Using the VCCT formula for quadrilateral elements [34], the energy release rate was calculated as:

$$
G_{I}=-\frac{Z_{i}\left(2 u_{j}\right)}{2 l_{i j}}
$$




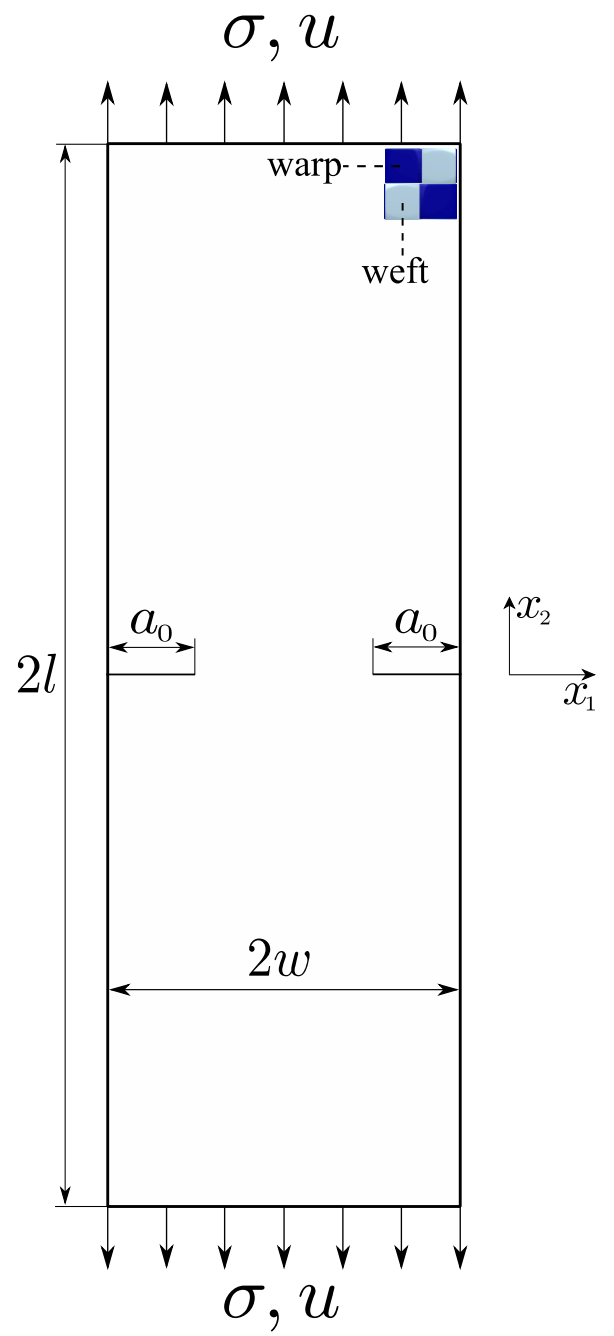

Figure 2 - Double Edge Notch Tension (DENT) specimen

where $Z_{i}$ is the load at the crack tip node $i$, and $u_{j}$ is the displacement of node $j$, both along the $x_{1}$ direction. The element length along the $x_{2}$ direction between nodes $i$ and $j$ is $l_{i j}$, as shown in Figure 3 .

In order to further simplify the expression of the correction factor, and provide a general formulation that could be used with the majority of standard balanced woven CFRP, the concept of Trace Theory [35] was employed, which exploits the similarity in the various composite systems available commercially. Table 1 lists the elastic properties of the most popular 2D woven composite materials, including the trace of the plane stiffness matrix, $\operatorname{tr}(Q)$, the equivalent modulus in plane stress, $E$, the two dimensionless parameters that take into account the orthotropy of the material, $\lambda$ and $\rho$, and the normalised values (with respect to the trace) of the equivalent modulus, $E^{*}$, and elastic modulus, $E_{11}^{*}$, respectively. Trace Theory shows that the normalised values of the elastic properties are constant. Consequently, $\lambda$ and $\rho$ should not change for a given class of material systems. For 2D woven CFRP composites, it was observed that the normalised values of the equivalent and elastic moduli could be considered constants (because of the very small coefficient of variation, CV\%) but the parameter $\rho$ changes substantially $(\mathrm{CV} \%=13.7)$. The $95 \%$ confidence interval for $\rho$ was found to be: $6.2 \leq$ $\rho \leq 8.3$. 


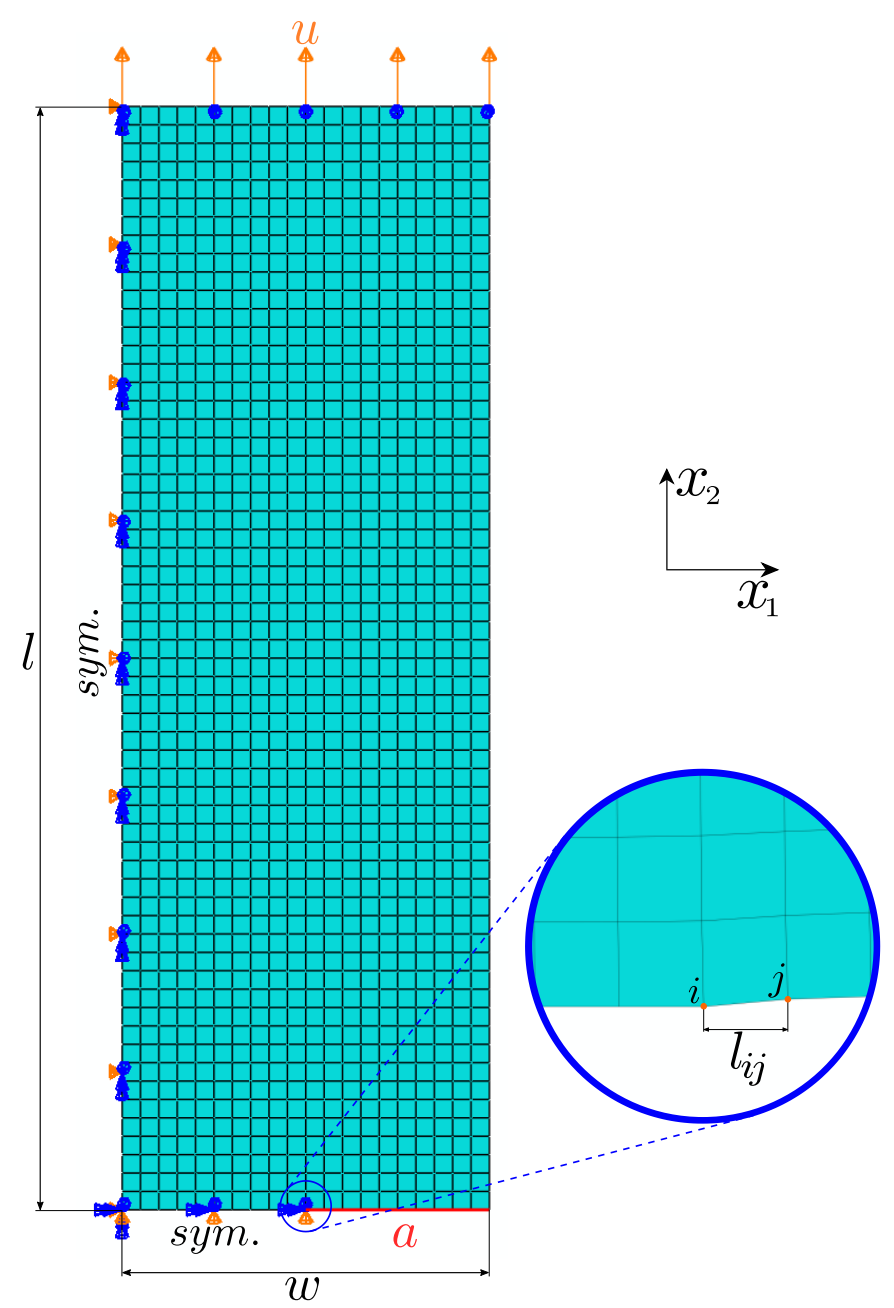

Figure 3 - 2D DENT quarter specimen finite element model for VCCT analysis

The variation in $\kappa$ in the range $6.2 \leq \rho \leq 8.3$ was found to be insignificant, with less than $1 \%$ change in the range $0 \leq \alpha \leq 1$, as shown in Figure 4 . Thus, $\kappa$ can be considered to depend solely on the shape parameter $\alpha$, and is calculated to be equal to:

$$
\kappa=\sqrt{\tan \frac{\pi \alpha}{2}}(1.4295-0.0374 \alpha)
$$

Thus the energy release rate reads:

$$
G_{I}=\frac{1}{\grave{E}} w \sigma^{2} \kappa^{2}
$$

Making use of the previous observation, that $E^{*}$ and $E_{11}^{*}$ can both be considered constant, Eq. (13) can also be rewritten as:

$$
G_{I}=\frac{E_{11}^{*}}{E_{11} \dot{E}^{*}} w \sigma^{2} \kappa^{2}=\frac{2}{E_{11}} w \sigma^{2} \kappa^{2}
$$

where $E_{11}^{*} / E^{*}=0.47 / 0.23 \approx 2$ (see Table 1$)$. 
Table 1 - Elastic and orthotropic properties for commercially available and tested 2D woven CFRP composite materials

\begin{tabular}{|c|c|c|c|c|c|c|c|c|c|c|}
\hline Material & $\begin{array}{c}E_{11} \\
{[\mathrm{GPa}]}\end{array}$ & $\begin{array}{c}E_{22} \\
{[\mathrm{GPa}]}\end{array}$ & $\begin{array}{c}G_{12} \\
{[\mathrm{GPa}]}\end{array}$ & $\begin{array}{c}v_{12} \\
{[-]}\end{array}$ & $\begin{array}{l}\operatorname{tr}(Q) \\
{[\mathrm{GPa}]}\end{array}$ & $\begin{array}{c}\dot{E} \\
{[\mathrm{GPa}]}\end{array}$ & $\begin{array}{c}\lambda \\
{[-]}\end{array}$ & $\begin{array}{l}\rho \\
{[-]}\end{array}$ & $\begin{array}{l}\dot{E}^{*} \\
{[-]}\end{array}$ & $\begin{array}{c}E_{11}^{*} \\
{[-]}\end{array}$ \\
\hline $\begin{array}{l}\text { Tencate TC250-HTS40 } \\
\text { 12k Plain weave [36] }\end{array}$ & 59.7 & 59.2 & 3.58 & 0.039 & 126.2 & 27.7 & 1 & 8.25 & 0.22 & 0.47 \\
\hline $\begin{array}{l}\text { Cytec EP2202-T650 } \\
\text { 3k Plain weave [37] }\end{array}$ & 63.7 & 64.4 & 4.45 & 0.053 & 137.4 & 31.7 & 0.99 & 7.14 & 0.23 & 0.46 \\
\hline $\begin{array}{l}\text { Cytec 5320-1-T650 } \\
\text { 3k Plain weave [38] }\end{array}$ & 68.9 & 68.5 & 5.07 & 0.053 & 147.9 & 35.0 & 1 & 6.72 & 0.24 & 0.47 \\
\hline $\begin{array}{l}\text { Hexcel 8552-AS4 } \\
\text { 3k Plain weave [39] }\end{array}$ & 66.1 & 66.6 & 4.96 & 0.046 & 142.9 & 33.9 & 0.99 & 6.63 & 0.24 & 0.46 \\
\hline $\begin{array}{l}\text { *Material } 1 \\
3 \mathrm{k} 2 \times 2 \text { Twill weave [40] }\end{array}$ & 60.6 & 61.6 & 5.01 & 0.042 & 132.4 & 32.4 & 0.98 & 6.06 & 0.24 & 0.46 \\
\hline \multirow[t]{4}{*}{$\begin{array}{l}* * \text { Material } 2 \\
6 \mathrm{k} 5 \mathrm{HS} \text { weave }\end{array}$} & 62.6 & 62.0 & 3.69 & 0.030 & 132.1 & 28.8 & 1 & 8.59 & 0.22 & 0.47 \\
\hline & & & & & & & Mean & 7.23 & 0.23 & 0.47 \\
\hline & & & & & & & $\mathrm{SD}$ & 0.99 & 0.01 & 0.006 \\
\hline & & & & & & & CV\% & 13.7 & 4.6 & 1.4 \\
\hline
\end{tabular}

*Material 1 is Gurit SE 84LV-RC200T. The shear modulus was obtained from ASTM D7078 [41] standard tests.

**Material 2 is a $2 \mathrm{D}$ woven toughened epoxy resin system with intermediate modulus carbon fibres. Elastic properties were obtained from testing conducted according to ASTM D3039 [3] and ASTM D7078 [41] standards.

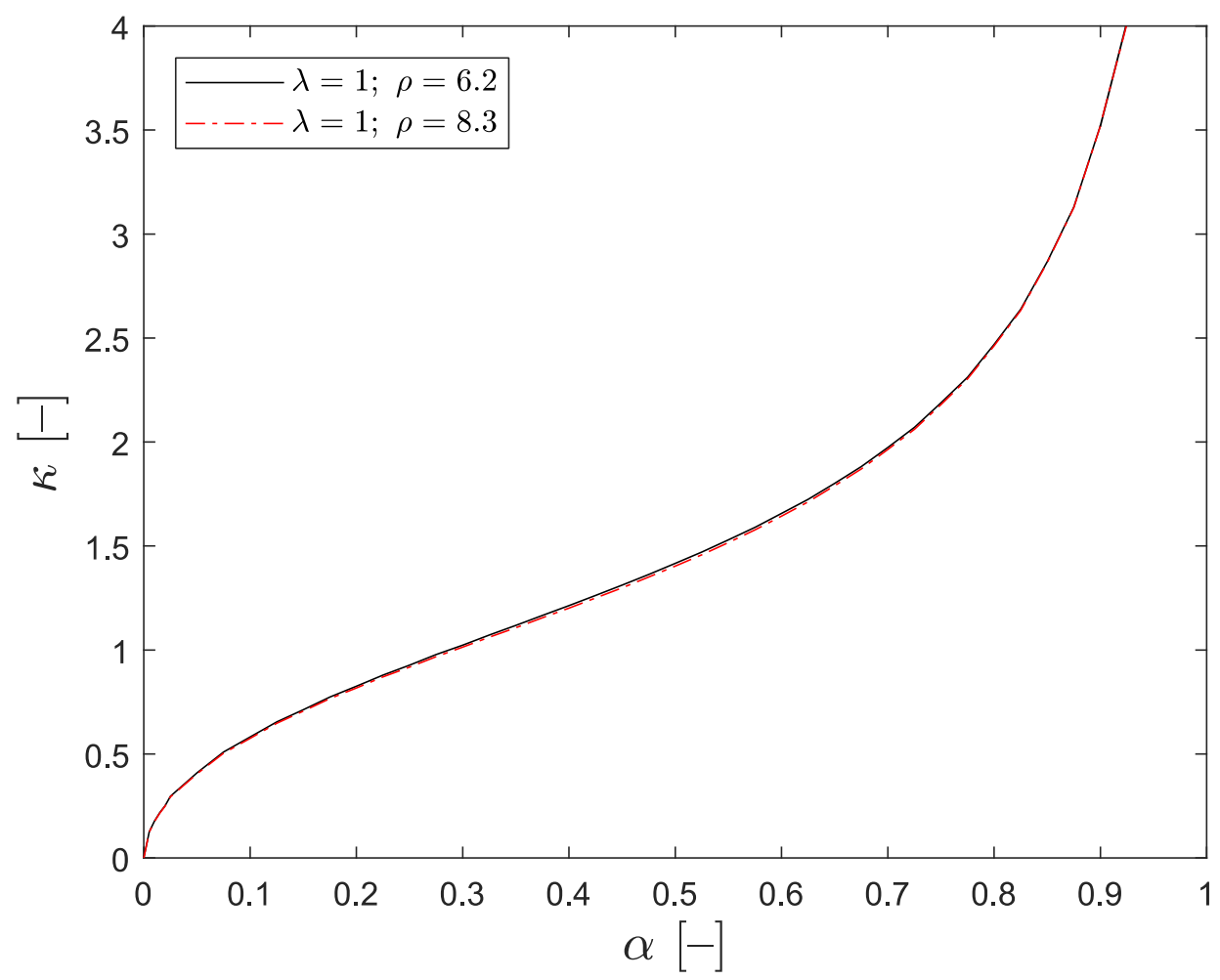

Figure 4 - Geometric correction factor variation with material orthotropy 
Equations (12) and (14) are particularly important because they avoid the need to recalculate $\kappa$ for 2D woven CFRP materials, eliminating the requirement of FE modelling in the data reduction, and making it possible to calculate the energy release rate knowing only the Young's modulus in the longitudinal direction. Since the correction factor $\kappa$ increases monotonically with crack extension (positive geometry specimen [17]), unstable fracture for each specimen occurs at some peak load, $P_{u}$. The corresponding nominal stress and peak load varies with specimen size according to a size effect law, $\sigma_{u}=\sigma_{u}(w)$. This size effect law can be obtained by using one of the regression fits recommended by Bažant and Planas [17]. These size effect laws, derived for finite size specimens, capture the deviation of small specimens from LEFM, while providing the asymptotic LEFM solutions for an infinite body, for the steady-state fracture toughness, $R_{S S}$, and the critical effective crack tip extension with a semi-infinite crack, $c_{f}$ [17]. This $c_{f}$ refers to the effective crack tip propagation required for the full development of the fracture process zone around the crack, at which point the propagation becomes self-similar. The $R_{S S}$ value is thus reached once the effective crack length exceeds $c_{f}$. Furthermore, this $c_{f}$ value is proportional to the fully developed length of the fracture process zone, $l_{f p z}$, in itself an intrinsic material parameter, which is calculated by the following relationship [17]:

$$
l_{f p z}=\frac{c_{f}}{\left(1-\frac{1}{2 \pi \eta}\right)}
$$

where $\eta$ is a material parameter that depends on the softening behaviour of the quasibrittle material. Table 2 presents these regressions, with corresponding formulas.

Table 2 - Size effect law regression fits

\begin{tabular}{|c|c|c|c|c|}
\hline Regression fit & Formula & Fitting parameters & $c_{f}$ & $R_{S S}$ \\
\hline Bilogarithmic & $\ln \sigma_{u}=\ln \frac{M}{\sqrt{N+w}}$ & $M, N$ & $\frac{\kappa_{0}}{2 \kappa_{0}^{\prime}} N$ & $\frac{\kappa_{0}{ }^{2}}{E^{\prime}} M^{2}$ \\
\hline Linear regression I & $\frac{1}{\sigma_{u}^{2}}=\bar{A} w+\bar{C}$ & $\bar{A}, \bar{C}$ & $\frac{\kappa_{0}}{2 \dot{\kappa}_{0}} \frac{\bar{C}}{\bar{A}}$ & $\frac{\kappa_{0}^{2}}{E^{\prime}} \frac{1}{\bar{A}}$ \\
\hline Linear regression II & $\frac{1}{w \sigma_{u}^{2}}=\dot{A} \frac{1}{w}+\dot{C}$ & $\dot{A}, \dot{C}$ & $\frac{\kappa_{0}}{2 \dot{\kappa}_{0}} \frac{\dot{A}}{\dot{C}}$ & $\frac{\kappa_{0}^{2}}{E^{2}} \frac{1}{\dot{C}}$ \\
\hline
\end{tabular}

where $\kappa_{0}=\left.\kappa\right|_{\alpha=\alpha_{0}}$ and $\kappa_{0}=\partial \kappa /\left.\partial \alpha\right|_{\alpha=\alpha_{0}}$

The energy release rate at peak load, $G_{I c}$, for each specimen size, is tangential to the $R$-curve at a unique point, as shown in Figure 5. Thus the $R$-curve can be obtained as an envelope of the critical driving force curves of different sized specimens, by solving the following set of equations:

$$
\left\{\begin{array}{l}
G_{I}(\Delta a)=R(\Delta a) \\
\frac{\partial G_{I}(\Delta a)}{\partial \Delta a}=\frac{\partial R(\Delta a)}{\partial \Delta a}
\end{array}\right.
$$


Substituting the size effect law into the first of Eq. (16), a new equation is obtained for the material's $R$ curve, which is valid for all the tested specimen sizes.

$$
R(\Delta a)=\frac{1}{\mathrm{E}} w \sigma_{u}^{2} \kappa^{2}\left(\alpha_{0}+\frac{\Delta a}{w}\right)
$$

By assuming fixed shape parameters, including the initial crack length ratio $\alpha_{0}$, and recalling that the $R$ curve is a material parameter independent of specimen width $(\partial R / \partial w=0)$ [17], differentiating Eq. (17), giving:

$$
\frac{\partial}{\partial w}\left(w \sigma_{u}^{2} \kappa^{2}\right)=0
$$

Solving Eq. (18) for $w=w(\Delta a)$, and substituting $w$ back in Eq. (17), the $R(\Delta a)$-curve is obtained.

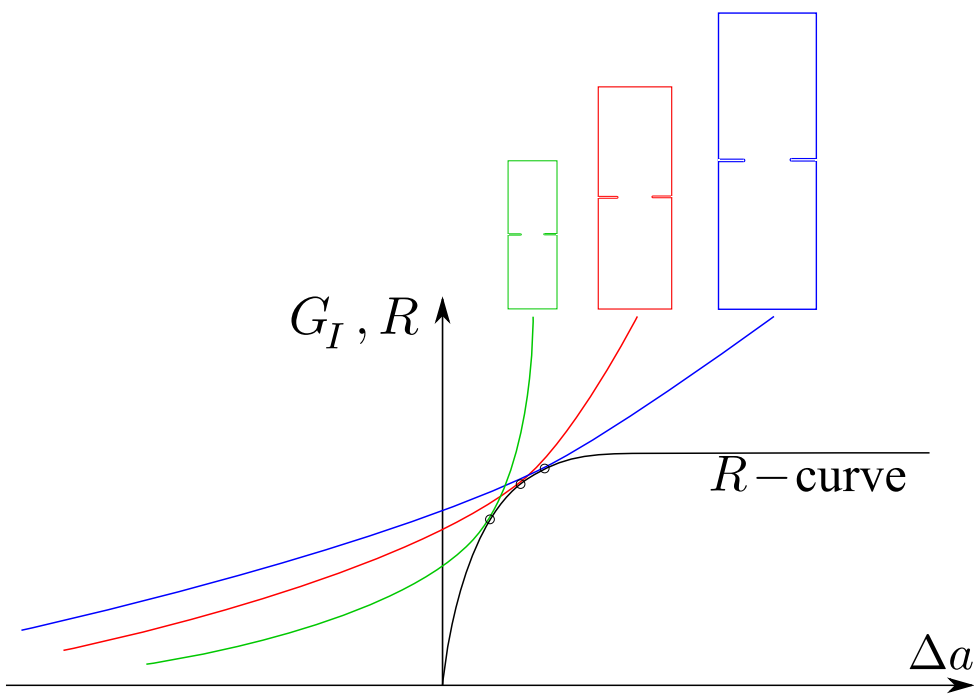

Figure $5-R$-curve as an envelope of peak load driving force curves for geometrically scaled specimens, including points of tangency

\subsection{Numerical sensitivity study of the dependence of the geometric correction factor on precrack tip radius}

The geometric correction factor $\kappa$ was investigated for the effect of precrack radius. A numerical analysis was performed for the smallest $(2 w=10 \mathrm{~mm})$ and largest $(2 w=30 \mathrm{~mm})$ experimentally tested specimens. The precrack tip radius, $r_{0}$, (see Figure 9) was varied from the theoretical slit crack $\left(r_{0}=0 \mathrm{~mm}\right)$ shown in the VCCT model of Figure 3, to more realistic radii values representing: (i) an actual sharp razor precrack $\left(r_{0}=\right.$ $0.15 \mathrm{~mm}$ ); (ii) a precrack milled with a cutter diameter of $1 \mathrm{~mm}\left(r_{0}=0.5 \mathrm{~mm}\right)$; and (iii) a precrack milled with a cutter diameter of $2 \mathrm{~mm}\left(r_{0}=1.0 \mathrm{~mm}\right)$. Considering $\alpha_{0}=0.5, \kappa$ was computed from the J-Integral around the initial precrack. Figure 6 depicts the stress distributions around these precracks in the quarter specimen FE models, (figure only presents the smallest specimen size, $2 w=10 \mathrm{~mm}$ ), where an increase in stress at the precrack tip can be observed with decreasing tip radius, for the same applied load. This suggests that the crack would start propagating earlier (at a smaller load value) for sharp precracks than for blunt milled precracks. 


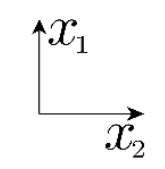

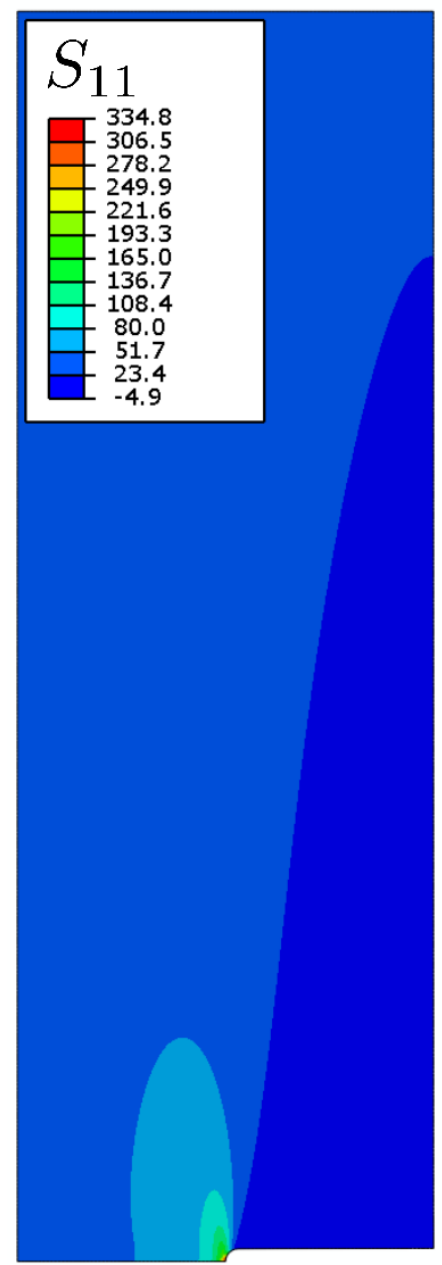

(a)

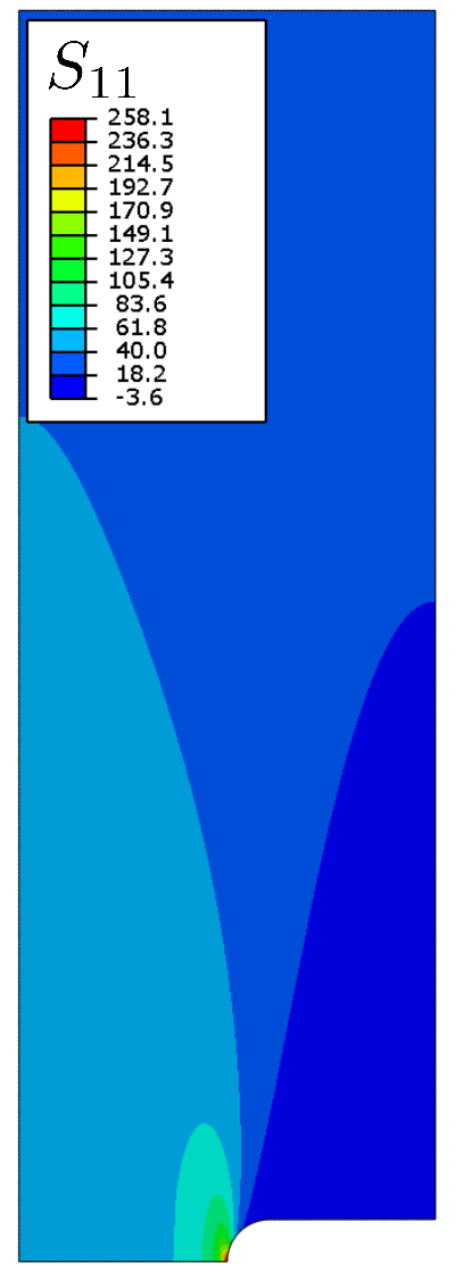

(b)

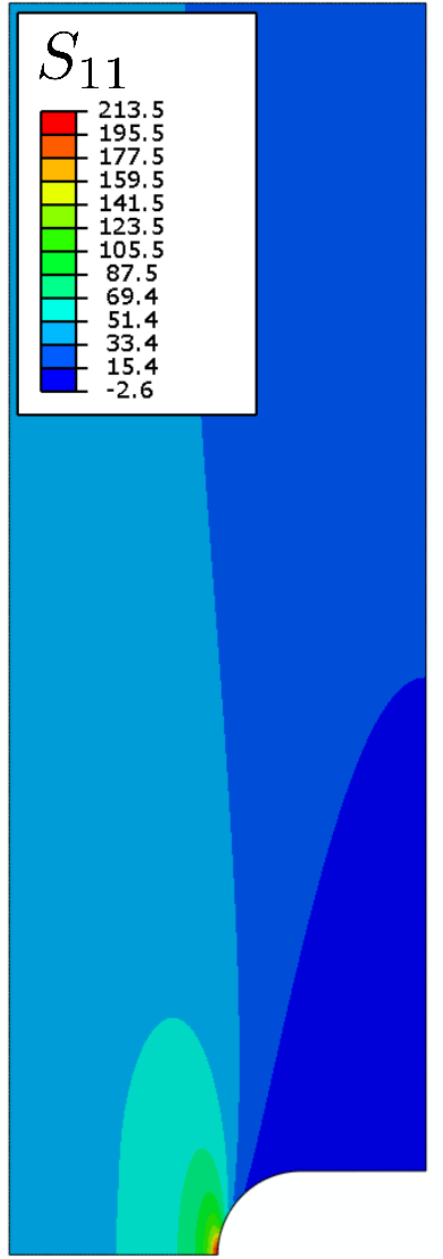

(c)

Figure 6 - Quarter specimen FE model stress distribution in the warp direction, $S_{11}$ (in MPa), for the (a) 0.3 mm razor blade precrack $(r=0.15 \mathrm{~mm})$, (b) $1 \mathrm{~mm}$ milled notch $(r=0.5 \mathrm{~mm})$, and (c) $2 \mathrm{~mm}$ milled notch $(r=1 \mathrm{~mm})$.

The correction factor $\kappa$ was then computed for a propagating slit crack, emanating horizontally from the precrack tip, in the range $0.5<\alpha<1$, for each of the different tip radii. The variation in $\kappa$ for the smallest and largest DENT specimens, using the three different precrack tip radii, can be observed in Figure 7. A significant difference in $\kappa$ was observed between the slit crack model and the models with realistic precrack tip radii, for $\alpha_{0}=0.5$. However, all models converged to the slit crack result once a slit crack was propagated from the precrack tip. As expected, the smallest specimen $(2 w=10 \mathrm{~mm})$ with the largest precrack tip radius $\left(r_{0}=1.0\right.$ $\mathrm{mm}$ ) converged slowest. Following this trend, the larger the specimen, the smaller the effect of the precrack tip radius on $\kappa$. However, since $R_{S S}$ is obtained as the asymptotic solution of the size effect law fit for an infinite size body [17], then the geometric correction factor for the steady-state fracture toughness should only be obtained from the slit crack VCCT solution, where the crack tip size is negligible when compared to the infinite size specimen. The inclusion of a non-zero precrack radius in the VCCT analysis would therefore be erroneous. 


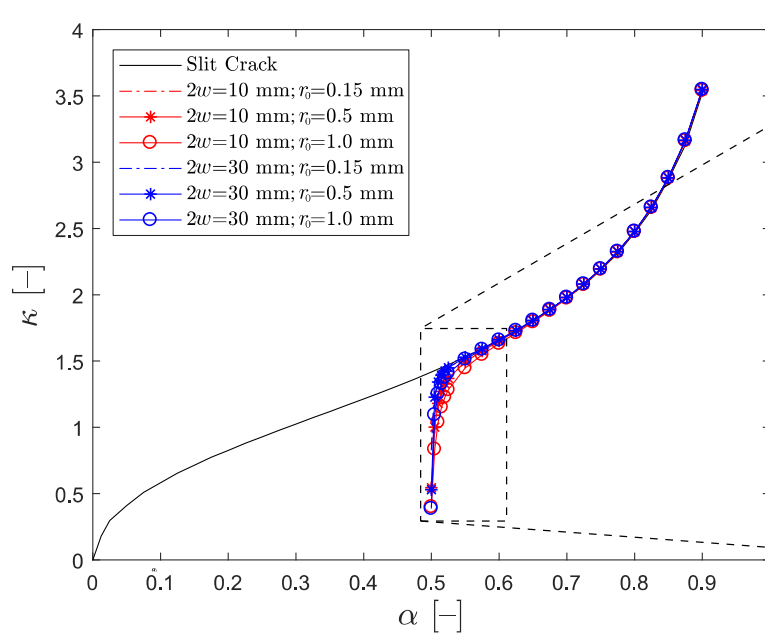

(a)

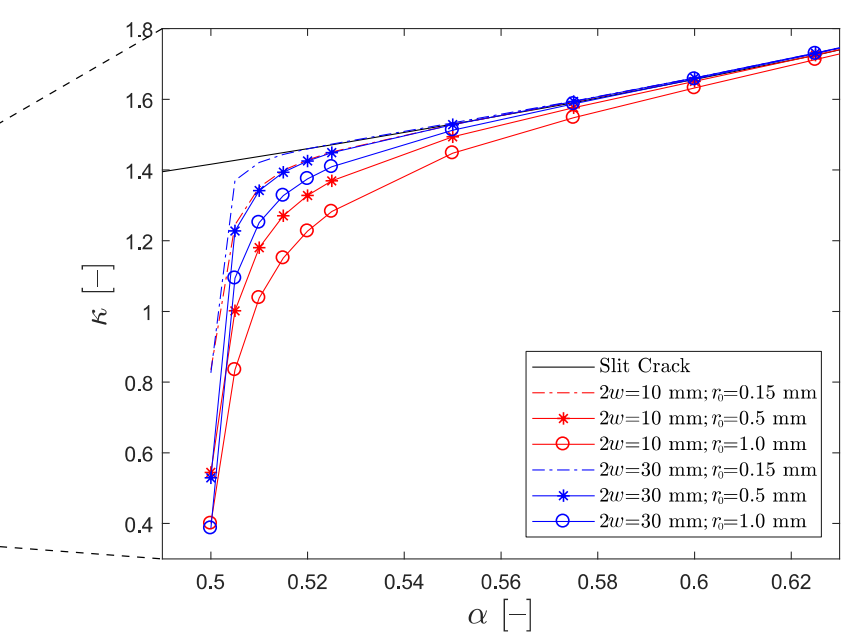

(b)

Figure $7-\kappa$ variation with precrack tip radius (a) with specific area of interest (b)

\section{Materials and test specimens}

Two 2D woven CFRP material systems were used to produce the required specimens:

1. Material $1-3 \mathrm{k} 2 \times 2$ Twill weave

i. $\quad[0]_{12}$ 12-ply laminate, nominal thickness of $2.75 \mathrm{~mm}$.

ii. $\quad[0]_{16} 16$-ply laminate, nominal thickness of $3.7 \mathrm{~mm}$.

2. Material 2 - 6k 5-Harness-Satin (5HS) weave

iii. $\quad[0]_{8} 8$-ply laminate, nominal thickness of $2.55 \mathrm{~mm}$.

iv. $\quad[0]_{12}$ 12-ply laminate, nominal thickness of $3.85 \mathrm{~mm}$.

The laminates were cured in an autoclave following the respective cure cycles recommended by the manufacturers, and the specimens were subsequently CNC milled using $2 \mathrm{~mm}$ diamond coated cutters. The thinner laminates from each material system were used to produce the DENT specimens, while the CT specimens were cut from the thicker laminates. The $10 \mathrm{~mm}$ long precracks of the CT specimens were cut using a sharp blade, $0.3 \mathrm{~mm}$ thick. The CT specimens for Material 2 also included a groove on either side of the specimen's precrack and crack propagation direction, to ensure that crack propagation occurred before the onset of back-end failure [42]. The grooves were machined using a $90^{\circ} \mathrm{v}$-shaped milling cutter. The base and grooved CT geometries are shown in Figure 8. A single side of each specimen was spray-coated with a thin layer of white paint, to facilitate the crack length measurement. Three CT specimens were tested for each material.

Two kinds of precracks were tested for the DENT geometry, one cut using a $1 \mathrm{~mm}$ milling cutter for the blunt precracks, and the other with the $0.3 \mathrm{~mm}$ thick blade for the sharp precracks. Hereon, the DENT specimens with sharp precracks will be referred to as Double Edge Crack Tension (DECT). The base DENT specimen geometry is shown in Figure 9. Table 3 lists all the tested sizes of scaled DENT and DECT geometries. The number of tested specimens for each material, size, and precrack radius is listed in Table 4. 


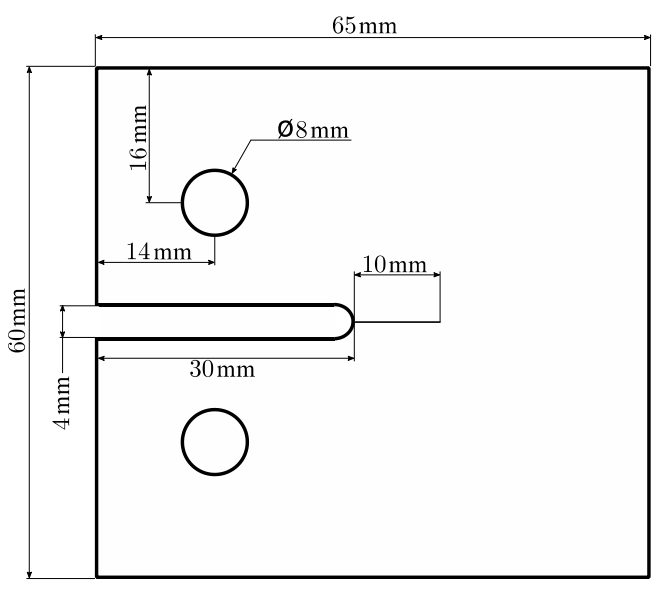

(a)

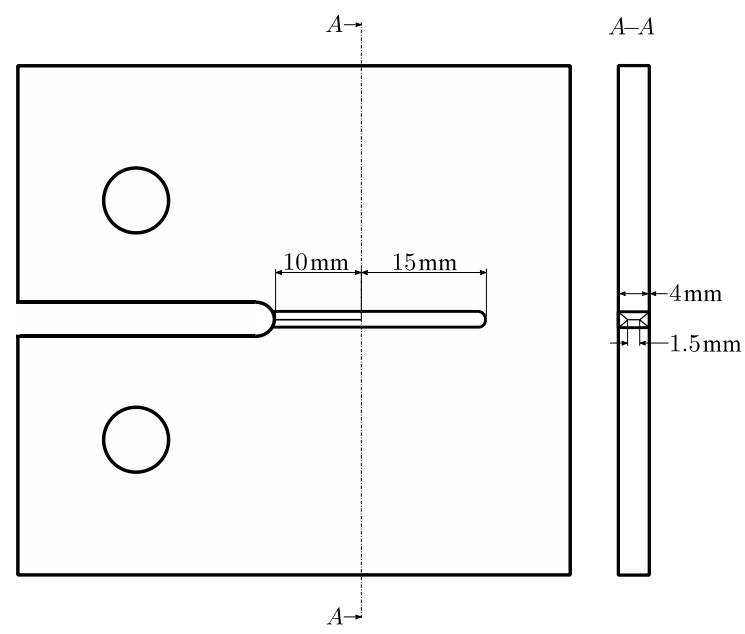

$(b)$

Figure 8 - (a) CT specimen, and (b) grooved CT specimen geometries
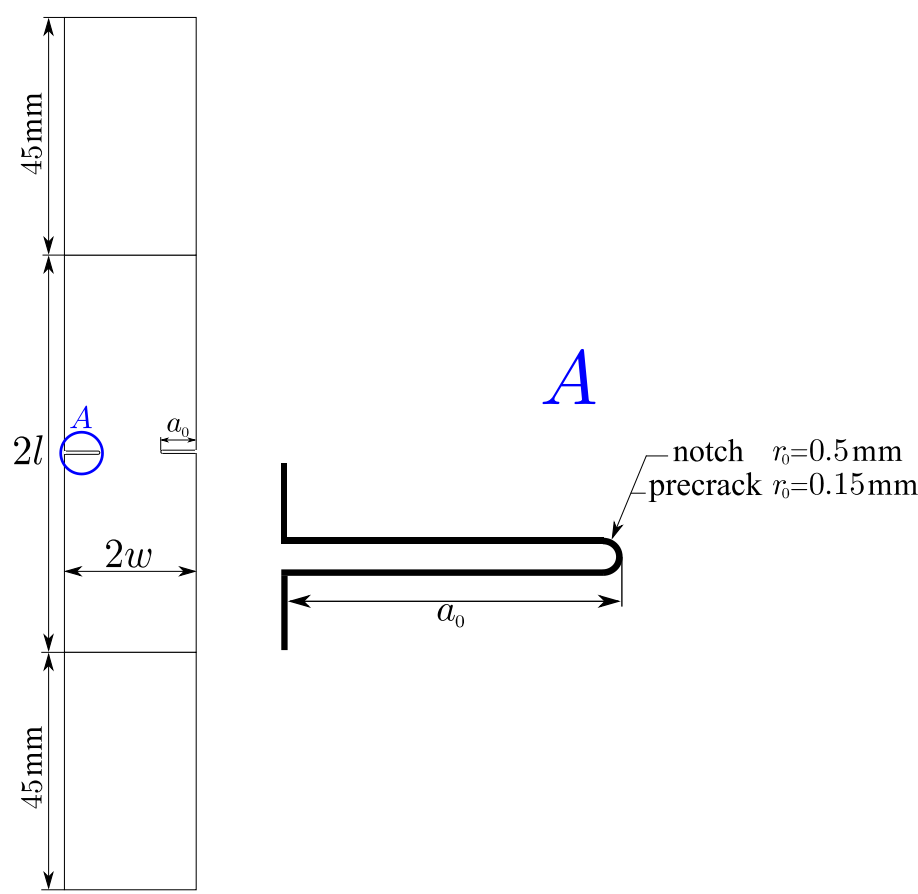

Figure 9 -DENT specimen geometry, including the 2 different tested precrack radii

Table 3 - DENT/DECT tested specimen geometries

\begin{tabular}{lccc}
\hline Specimen label & $2 w[\mathrm{~mm}]$ & $2 l[\mathrm{~mm}]$ & $a_{0}[\mathrm{~mm}]$ \\
\hline 10 & 10 & 30 & 2.5 \\
15 & 15 & 45 & 3.75 \\
20 & 20 & 60 & 5 \\
25 & 25 & 75 & 6.25 \\
30 & 30 & 90 & 7.5 \\
\hline
\end{tabular}




\section{Test setup and experimental results}

\subsection{CT results}

The CT specimens were tested with a crosshead displacement of $1 \mathrm{~mm} / \mathrm{min}$ in a Hounsfield tensile testing machine with a $50 \mathrm{kN}$ load cell. An LVDT was used to record the displacement between the two loading pins, while the crack length increments were recorded optically. Figure 10 shows the crack progression for a typical CT specimen test of Material 1. The load displacement curves obtained for Material 1 were characterised by few distinct load drops, accompanied by significant crack length increments. When using the area method data reduction scheme, two load peaks are required for each data point, so that these results could only provide a maximum of two fracture toughness values per specimen (3 load peaks). Such results are typical of brittle materials, as evidenced by a small overall fracture process zone around the crack, where little fibre pull-out and fibre bridging effects were observed during crack propagation. Initially, Material 2 was also tested using the base CT geometry. However, as depicted in Figure 11, back-end failure occurred after the initial load drop, with only a few millimetres of crack propagation. Thus, results of these specimens had to be omitted. The design was modified to include a groove along the precrack and ligament, measuring $25 \mathrm{~mm}$. The reduced nominal crosssection of $1.5 \mathrm{~mm}$ successfully mitigated back-end failure until the crack had propagated by $12-15 \mathrm{~mm}$, with around four load peaks per specimen. The failure of a typical grooved CT specimen of Material 2 is shown in Figure 12, where the crack is assumed to propagate between the tips of the two grooves (verified by qualitative observation). This assumption is as subjective as the optical crack length measurement used in all CT experiments. The few and distinct load drops observed with both materials did not allow for many fracture toughness data points to be obtained. Admittedly, heavier and more rigid grips could have possibly improved these CT results, by reducing the instability that occurs at the load drops [12]. However, such grips were not available at the time of testing. The crack length measurement, identified as the crack tip in the painted surface, proved hard to measure for all the different CT specimens.

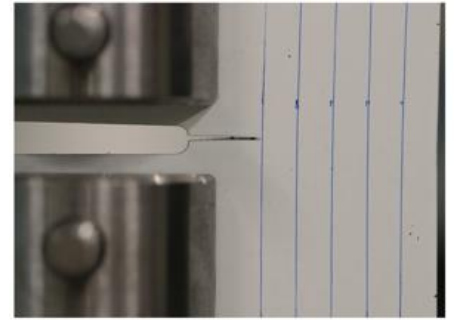

$(a)$

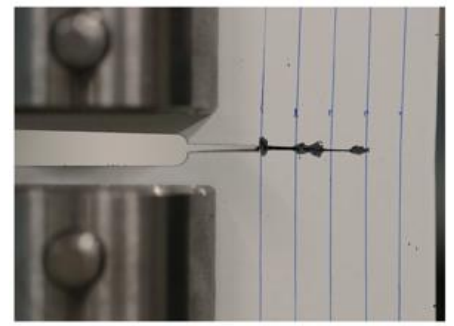

(c)

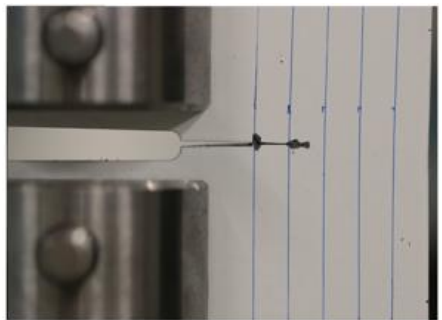

(b)

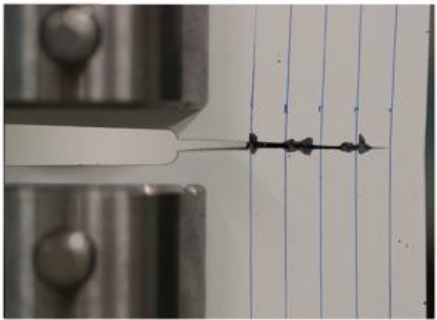

$(d)$

Figure 10 - Material 1 CT test: (a) before initial crack propagation; (b) after initial propagation; (c) at intermediate propagation; (d) at end of test after final propagation 


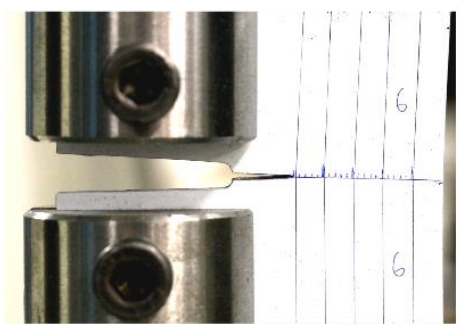

(a)

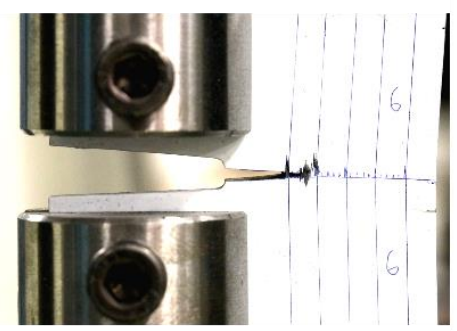

(c)

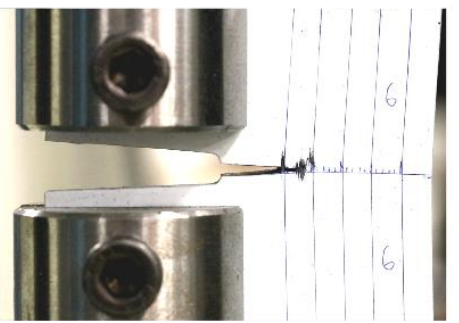

(b)

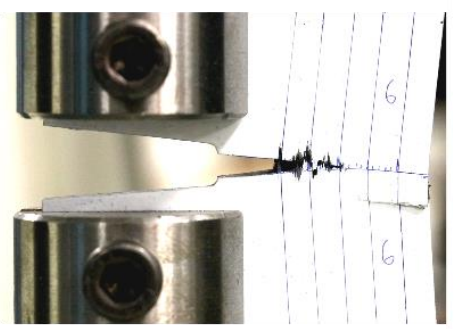

(d)

Figure 11 - Material 2 CT test: (a) before initial crack propagation; (b) after initial propagation; (c) after initial back-end failure; (d) at end of test

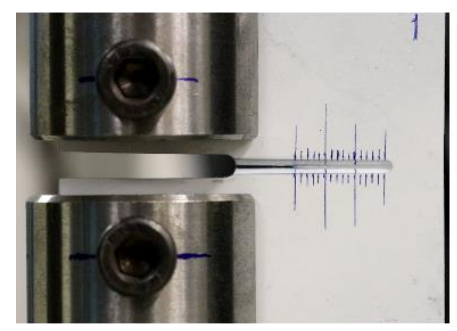

(a)

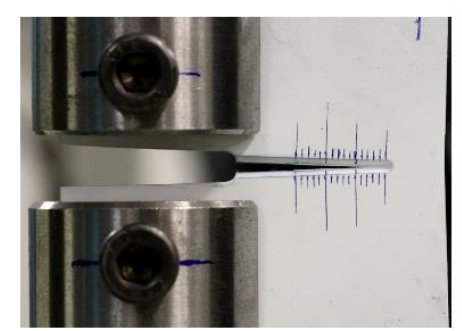

(c)

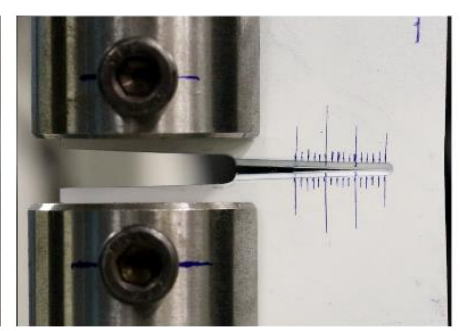

(b)

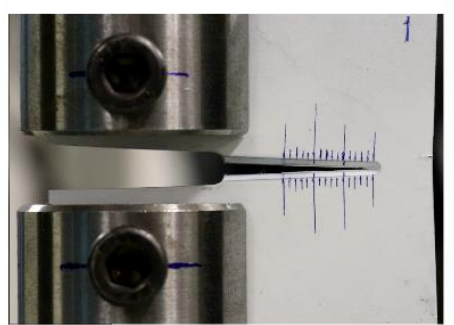

$(d)$

Figure 12 - Material 2 Grooved CT test: (a) before initial crack propagation; (b) after initial propagation; (c) at intermediate propagation; (d) at end of test after initial back-end failure 


\subsection{DENT/DECT results}

The DENT and DECT specimens were tested at a speed of $1 \mathrm{~mm} / \mathrm{min}$ in a Zwick Roell Z100 tensile testing machine with a $100 \mathrm{kN}$ load cell. The peak nominal stresses obtained for each set of specimens are listed Table 4. Figure 13 shows different sizes of DENT specimens for Material 2, while Figure 14 shows the fractured ligaments of the same specimens post-testing. No evident difference was noted visually between the fractured DECT and DENT specimens of each material, as shown in Figure 15, except that Material 1 had less visible damage around the fractured ligament when compared to Material 2.

Table 4 - DENT/DECT average peak nominal stress, $\sigma_{u}$ (in MPa), and its standard deviation (in () brackets), and the number of tested specimens in each set (in \{\} brackets).

\begin{tabular}{lccccc}
\hline Specimen label & 10 & 15 & 20 & 25 & 30 \\
\hline Material 1 & & & & & \\
- DECT & $268(3)\{3\}$ & $190(10)\{3\}$ & $166(11)\{3\}$ & $165(5)\{3\}$ & $144(9)\{3\}$ \\
- DENT & $262(7)\{3\}$ & $225(10)\{3\}$ & $180(6)\{3\}$ & $172(11)\{3\}$ & $145(3)\{3\}$ \\
& & & & & \\
Material 2 & & & & & \\
- DECT & $412(20)\{8\}$ & $357(28)\{8\}$ & $311(7)\{6\}$ & $302(33)\{7\}$ & $294(12)\{6\}$ \\
- DENT & $431(14)\{8\}$ & $372(12)\{9\}$ & $324(14)\{7\}$ & $299(14)\{6\}$ & $290(19)\{6\}$
\end{tabular}

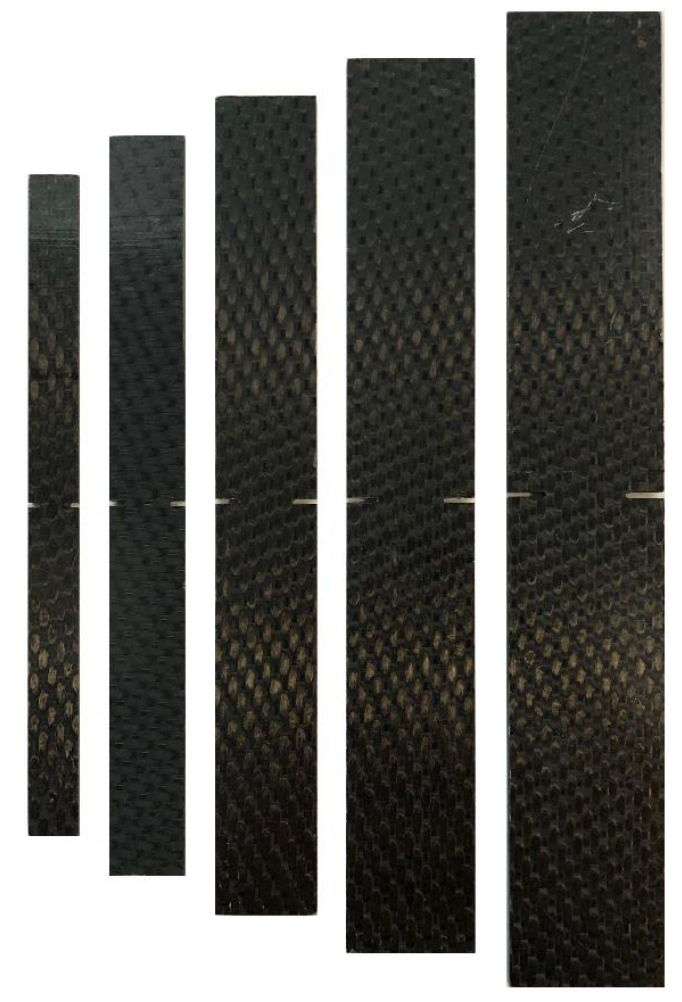

Figure 13 - Untested DENT specimens for Material 2 (all sizes) 


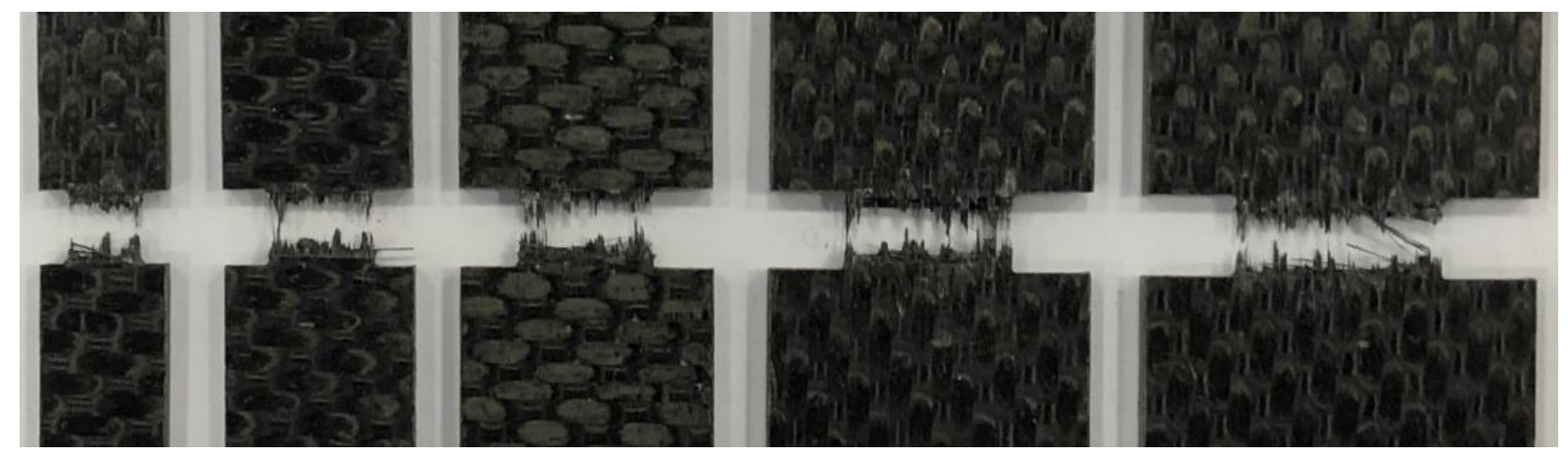

Figure 14 - Fractured DENT specimens for Material 2 (all sizes)

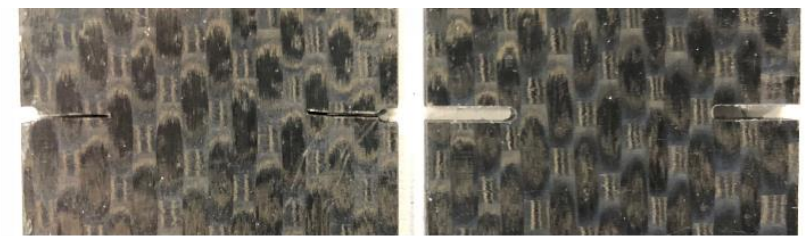

$(a)$

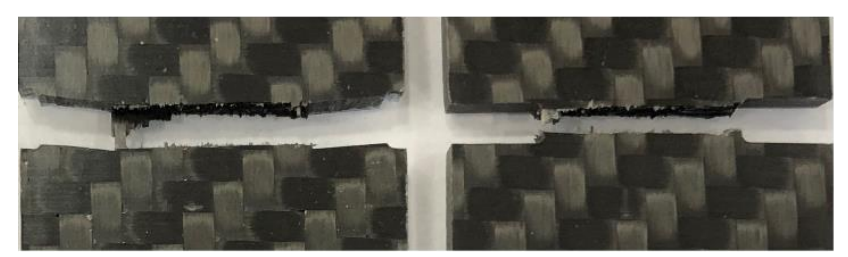

(b)

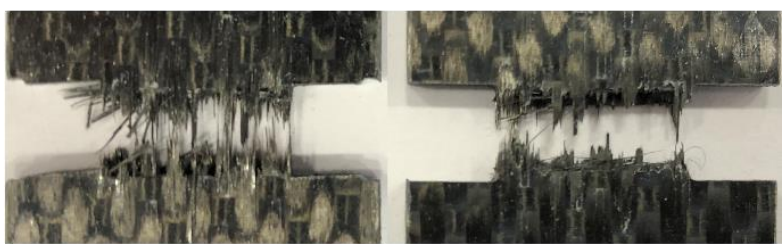

(c)

Figure 15 - DECT (right) and DENT (left) specimens: untested (a); tested Material 1 (b); tested Material 2 (c)

The difference in peak nominal stress between DENT and DECT specimens is also sufficiently small for both materials, when compared with the scatter in results. The variation in each size set was found to be greater for the DECT specimens, especially for Material 2, where the observed peak nominal stresses were higher than those of Material 1. This larger variation could be attributed to the decreased geometric accuracy in the length of the manually cut sharp precracks. Considering the nominal widths of the specimens, a $\pm 0.5 \mathrm{~mm}$ difference in precrack length could result in a significant margin of error in $\alpha_{0}$ values, especially for the smaller specimens. This would introduce subsequent errors in the size effect law calculation, where the scaled specimens require equal $\alpha_{0}$ values. However, the machining tolerances achievable using industrial CNC milling machines is quite high, usually within the range of $\pm 0.01 \mathrm{~mm}$, so that the error in precrack lengths is not significant.

Using the values in Table 4, a nonlinear least-squares Levenberg-Marquardt method was used to fit the bilogarithmic size effect regression, while a linear fit was used for the other two regressions, including their 95\% confidence intervals. The bilogarithmic regression gave the best fit for the DECT and DENT data of both materials. The size effect fits for Material 1 and Material 2 are shown in Figure 16 and Figure 17 respectively. 


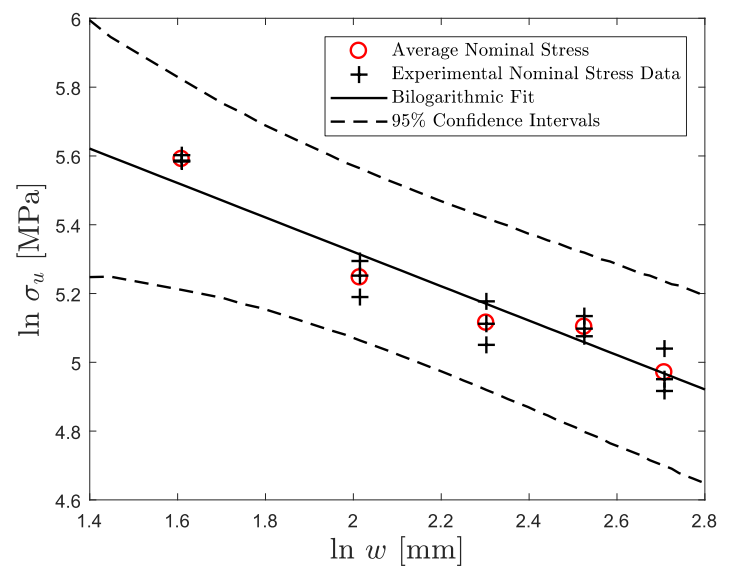

(a)

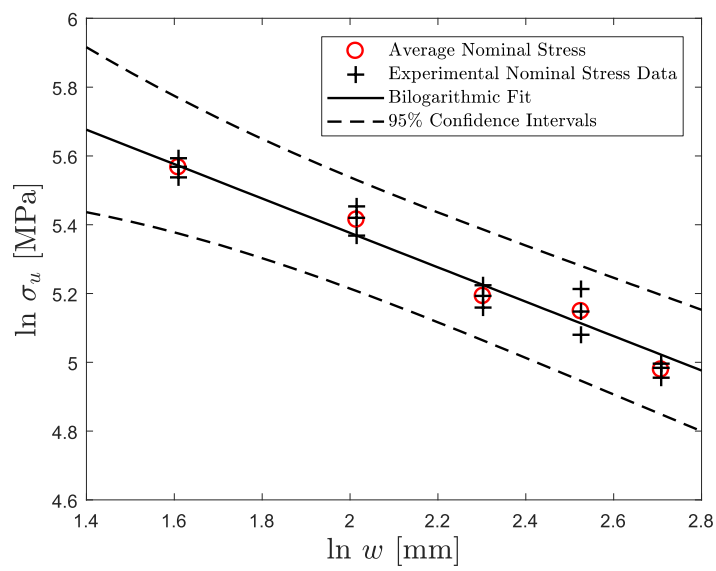

(b)

Figure 16 - Size effect laws - Bilogarithmic fit for (a) DECT and (b) DENT specimens for Material 1

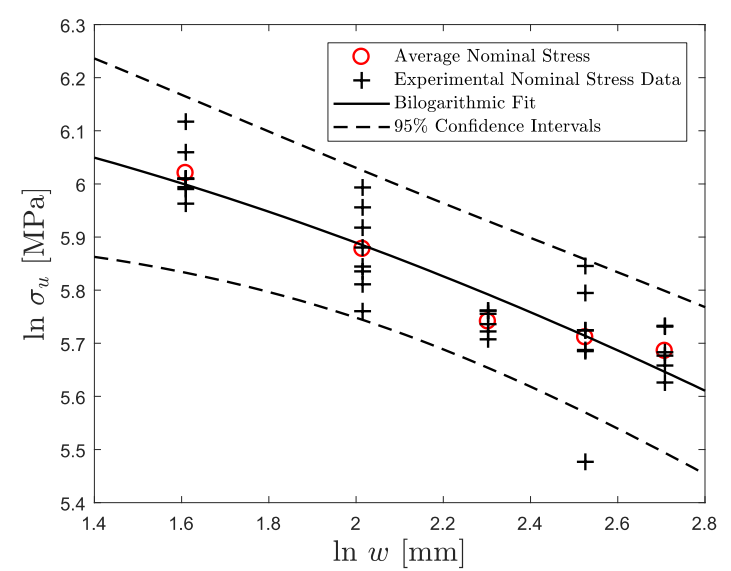

(a)

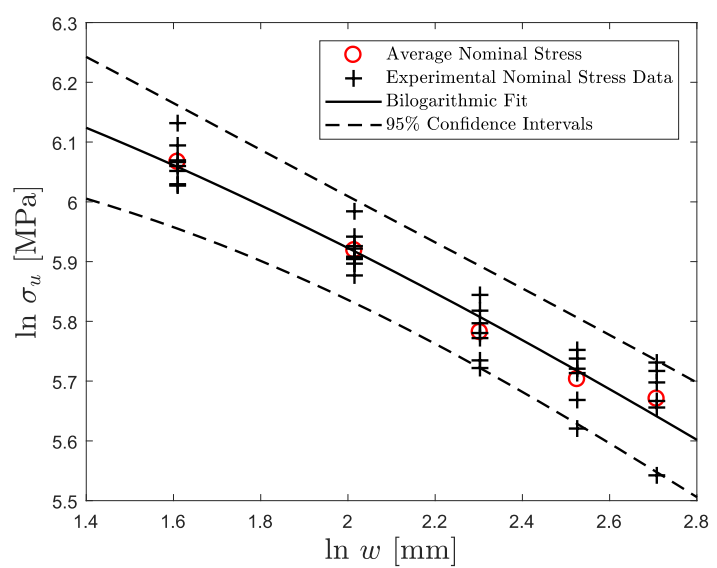

(b)

Figure 17 - Size effect laws - Bilogarithmic fit for (a) DECT and (b) DENT specimens for Material 2

\subsection{Mode I intralaminar fracture toughness results}

The fracture toughness results obtained from the DECT and DENT experiments are presented for each material, in Figure 18 and Figure 19. The $G_{I}(\Delta a)$ curves, numerically derived for different specimen sizes (in blue), including those specific to the experimentally tested sizes (in red), were used to obtain each of the $R$ curves. The $95 \%$ confidence interval of each $R$-curve was obtained by substituting the $95 \%$ confidence limits of the size effect laws into the $G_{I}(\Delta a)$ equation and obtaining new $R$-curve envelopes. The bilogarithmic size effect fitting coefficients $(M, N), c_{f}$ and $R_{S S}$ for each material are listed in Table 5 . The $R$-curves for both materials show that there is no significant difference between the DECT and DENT specimens, since their values fall within the confidence limits of the other. Each material's DECT and DENT results are also compared with the data points obtained from CT tests in Figure 20. These plots show an agreement in the $R_{S S}$ obtained from stable and unstable crack propagation techniques, with the CT data points falling within the confidence intervals of the size effect test results. These plots also show a lack of CT data around the rising part of the $R$ - 
curve, unlike the results of the DECT and DENT tests which better capture the development of the fracture process zone. The average $R_{S S}$ values obtained from CT specimens are also listed in Table 5 .

The relatively brittle behaviour of Material 1 can be observed from both the nature of the $R$-curves (very short $c_{f}$ ), and from the few $\mathrm{CT}$ data points, all occurring at large $\Delta a$ values. The $R_{s s}$ value is also significantly lower than the one of Material 2, and other $R_{S S}$ values observed in literature for similar materials [2]. In fact, since all the $G_{I}(\Delta a)$ curves for the tested specimens of Material 1 are tangential to the $R$-curve at the plateau region, it was concluded that at this length scale, this composite can be considered to follow a Linear Elastic Fracture Mechanics (LEFM) behaviour limit for perfectly brittle materials [17]. The almost negligible value of $c_{f}$ for this material conflicts with the assumption made by Catalanotti et al. [2], formulated while testing UD cross-ply laminates, of a sharp crack tip at peak load.

For Material 2, a tougher response was observed in both stable and unstable test regimes. This was corroborated with a higher $R_{S S}$ value and a longer $c_{f}$ than those of Material 1. This notable difference in fracture toughness between the tested materials is suspected to be a result of the differences in fibre strength, matrix toughness, and the fibre-matrix interface, while the different weave architecture could play a minor role. Some of the CT data for Material 2 falls slightly outside of the DENT confidence intervals. However, the CT data points are highly sensitive to the measured crack lengths. Locating the exact tip of a crack in a specimen's painted surface is not an effective and objective method for measuring the effective crack length. The aforementioned methods that provide a more accurate determination of the crack tip position, such as DIC [29], have not been pursued in the knowledge that industry is seeking quicker and more straight-forward approaches. Furthermore, theoretically, during the crack propagation in such composite materials, especially those with a woven reinforcement, the concept of a single crack tip is an approximation, since, in reality, crack propagation in each ply may be self-similar, and may involve multiple failure mechanisms along various constituent surfaces.

Table 5 - Steady-state fracture toughness $\left(R_{S S}\right)$, critical crack extension $\left(c_{f}\right)$, and size effect fitting coefficients $(M, N)$

\begin{tabular}{ccccc}
\hline & $M[\mathrm{MPa} \sqrt{\mathrm{mm}}]$ & $N[\mathrm{~mm}]$ & $c_{f}[\mathrm{~mm}]$ & $R_{S S}\left[\mathrm{~kJ} / \mathrm{m}^{2}\right]$ \\
\hline Material 1 & & & & \\
$\bullet \quad$ DECT & 556.2 & $1 \times 10^{-5}$ & $4 \times 10^{-6}$ & 19.0 \\
$\bullet \quad$ DENT & 587.7 & $5.97 \times 10^{-4}$ & $1.93 \times 10^{-4}$ & 21.2 \\
$\bullet \quad$ CT & - & - & - & 28.9 \\
Material 2 & & & & \\
- DECT & 1259.0 & 4.77 & 1.54 & 108.7 \\
$\bullet$ DENT & 1184.4 & 2.67 & 0.86 & 96.2 \\
- CT & - & - & - & 111.5 \\
\hline
\end{tabular}




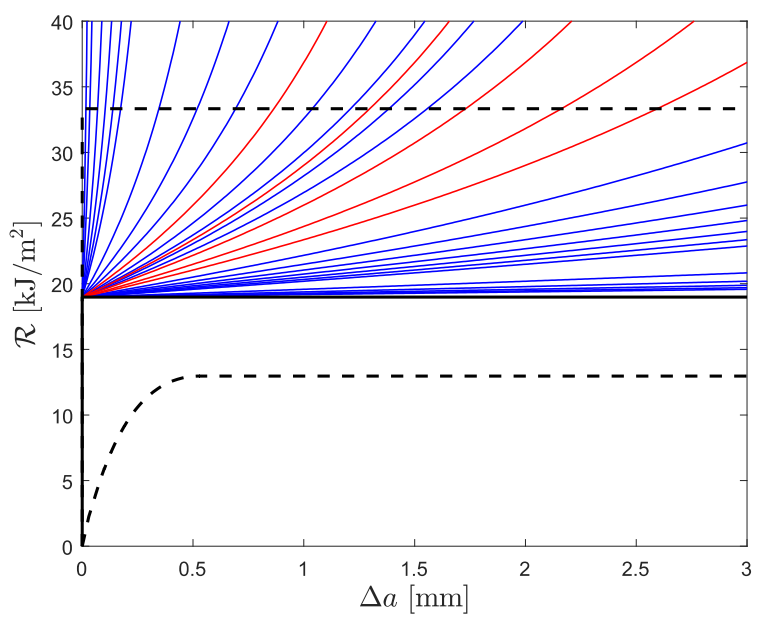

(a)

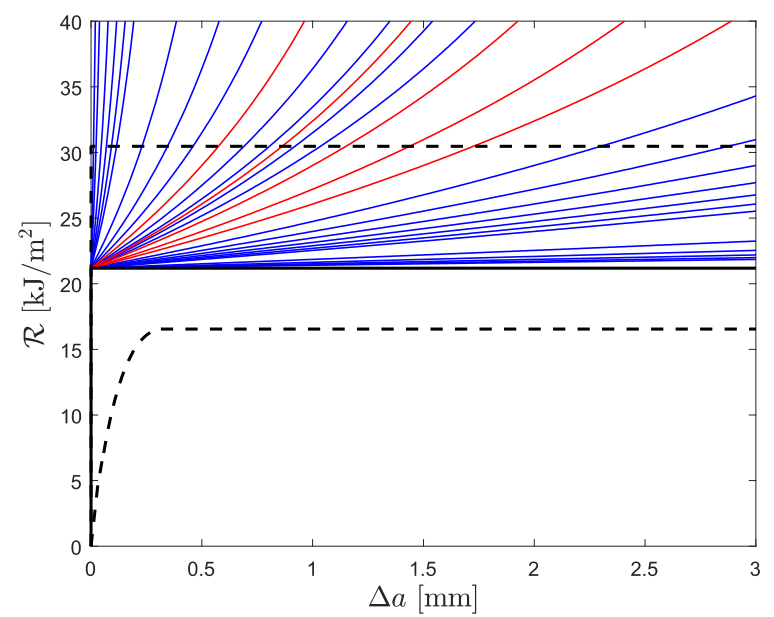

(b)

Figure $18-R$-curves (in black) with 95\% confidence limits (in dashed black) for (a) DECT and (b) DENT specimens for Material 1

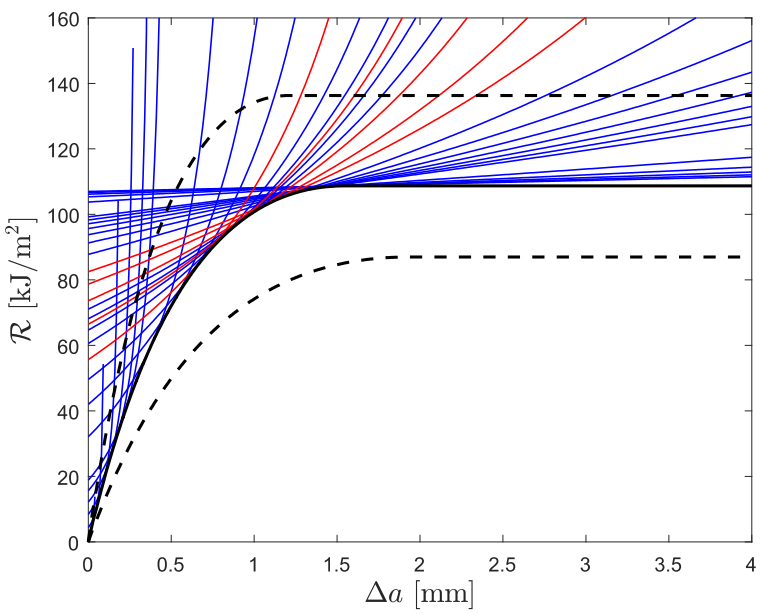

(a)

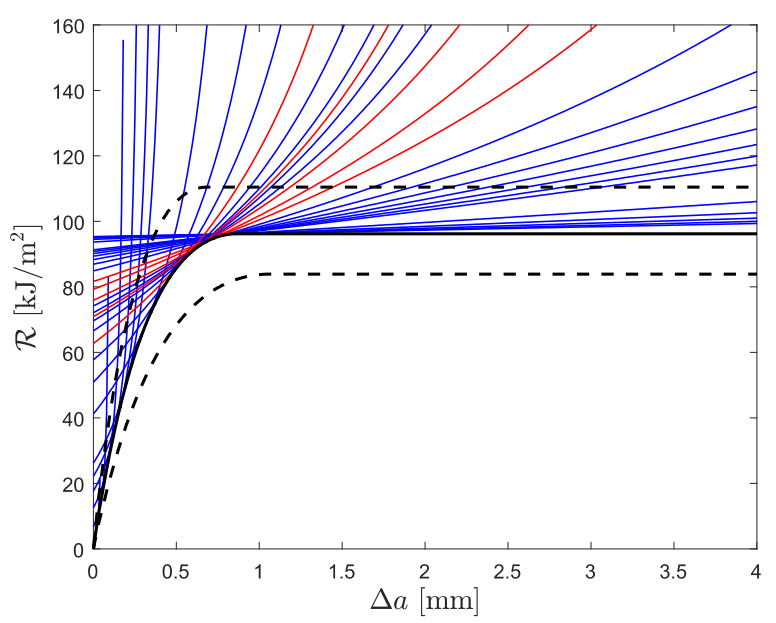

(b)

Figure $19-R$-curves (in black) with 95\% confidence limits (in dashed black) for (a) DECT and (b) DENT specimens for Material 2

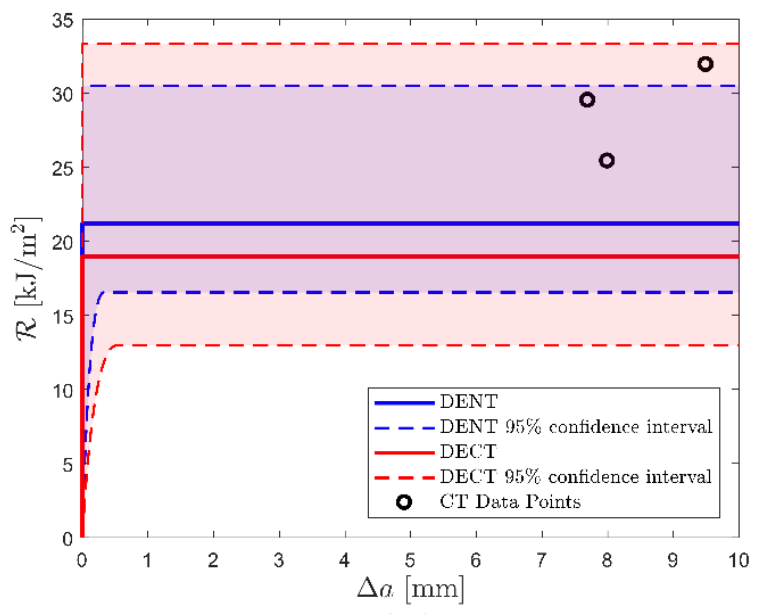

(a)

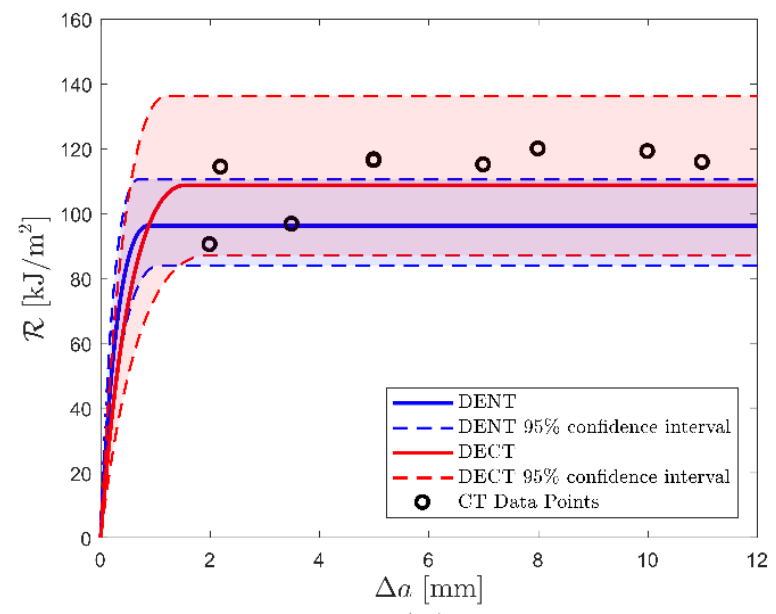

(b)

Figure 20 - $R$-curves with 95\% confidence limits from DECT/DENT, and CT data, for (a) Material 1, and (b) Material 2 


\section{Numerical study of the precrack tip radius effect on a DENT specimen using an embedded cell}

FE model

A FE model of a DENT specimen $(2 w=20 \mathrm{~mm})$ was generated in the software package Abaqus ${ }^{\circledR}$ [33], with the purpose of numerically analysing the effect of precrack tip radius on the peak load. The fracture morphology is also of interest, since it involves the longitudinal and transverse fracture of tows, and the degradation of the epoxy matrix.

The model consists of an embedded cell (EC) model, including an eight-ply stack plain weave along the ligament of the DENT specimen, surrounded by a homogenised mesoscale (ply-level) volume for the rest of the specimen (see Figure 21). The homogenised volume is intended to represent the mesoscopic elastic behaviour of the specimen, thus helping to reduce computational cost. The finite element model as well as the constitutive material models are briefly described in the following sections.

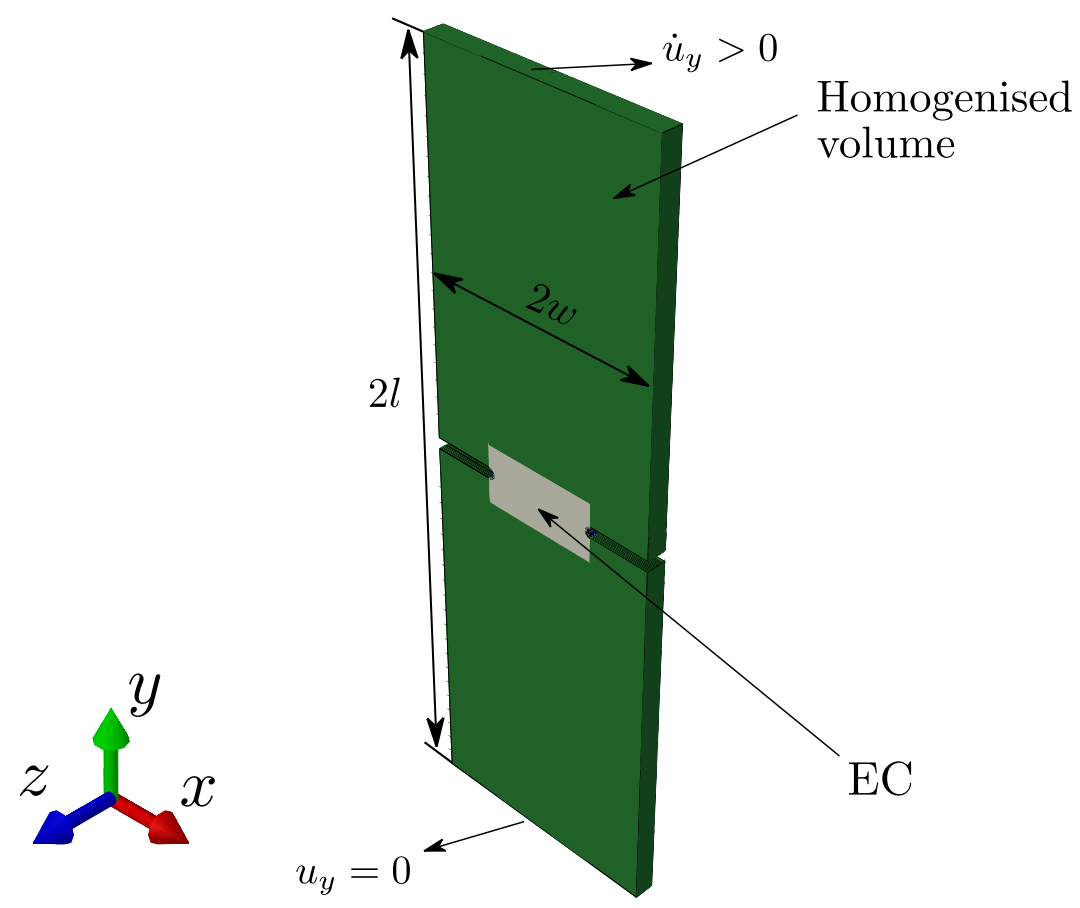

Figure 21 - FE model including the embedded cell and homogenised volume, with the applied BCs.

\subsection{Finite element model}

The total length, width and thickness of the computational model was $2 l=60 \mathrm{~mm}, 2 w=20 \mathrm{~mm}$ and $t=$ $3.2 \mathrm{~mm}$, respectively. The eight-ply stack EC had a width of $W_{E C}=10 \mathrm{~mm}$ and a total length of approximately $L_{E C}=5 \mathrm{~mm}$. The width of a compacted tow was $W_{\text {tow }}=2.2 \mathrm{~mm}$. The EC consisted of pre-compacted tows embedded in an epoxy matrix. The tow compaction was performed in a prior simulation, to obtain a more realistic representation of a cured laminate, as shown in Figure 22. Since the scope of this analysis was to analyse 
the crack propagation inside each tow rather than to compare the propagation in different weave patterns, a plain weave pattern was modelled for the tows, due to its simplicity.
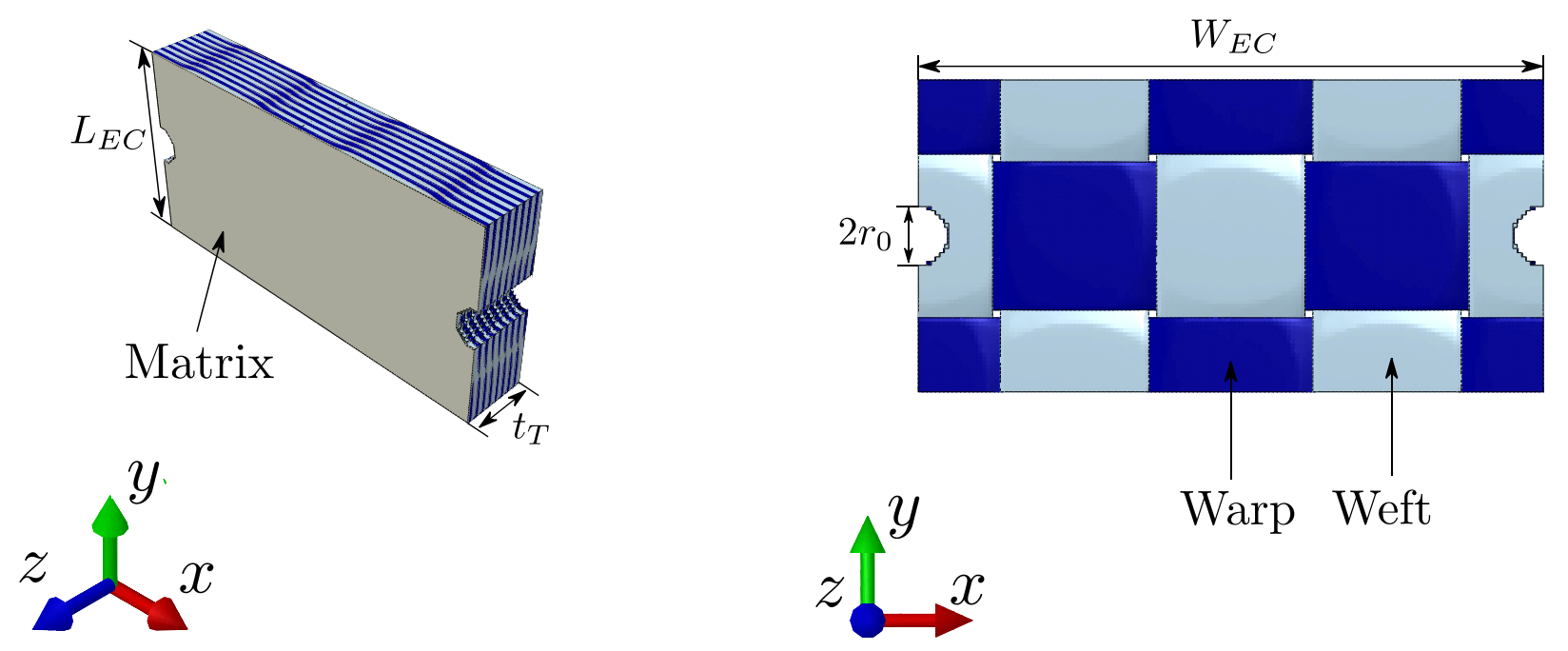

Figure 22 - EC displayed in an isometric view (left) and in a front view highlighting the weave pattern (right).

Figure 21 shows the complete FE model, subjected to the appropriate Boundary Conditions (BCs). The homogenised volume of the model was generated by offsetting the elements with one-hundred solid layers at the EC's boundaries, through orphan mesh capabilities. To represent the model's geometry, three-dimensional tetrahedral continuum solid elements (C3D4) were used to represent the matrix in between the EC's tows, while three-dimensional reduced integration linear brick elements (C3D8R) were used to discretise the tows and the homogenised volume. The average element size for the homogenous volume, tows and matrix was around 0.03 $\mathrm{mm}$. Two FE models were generated, including geometric precracks similar to the experimentally tested DENT and DECT specimens, with $r_{0}=0.5 \mathrm{~mm}$ and $r_{0}=0.15 \mathrm{~mm}$ respectively. The tips of each precrack were located in the ECs, created by the removal of elements. The $\alpha_{0}=0.5$ ratio was maintained, with precracks each having a length of $5 \mathrm{~mm}$. A comparison of the two models' precracks are shown in Figure 23.

\subsection{Constitutive material models}

An orthotropic linear elastic constitutive model was used to simulate the homogenised volume, since this part of the specimen would remain within the elastic limit behaviour throughout the specimen test. Thus, no material nonlinearity or damage behaviour was considered in this volume. 

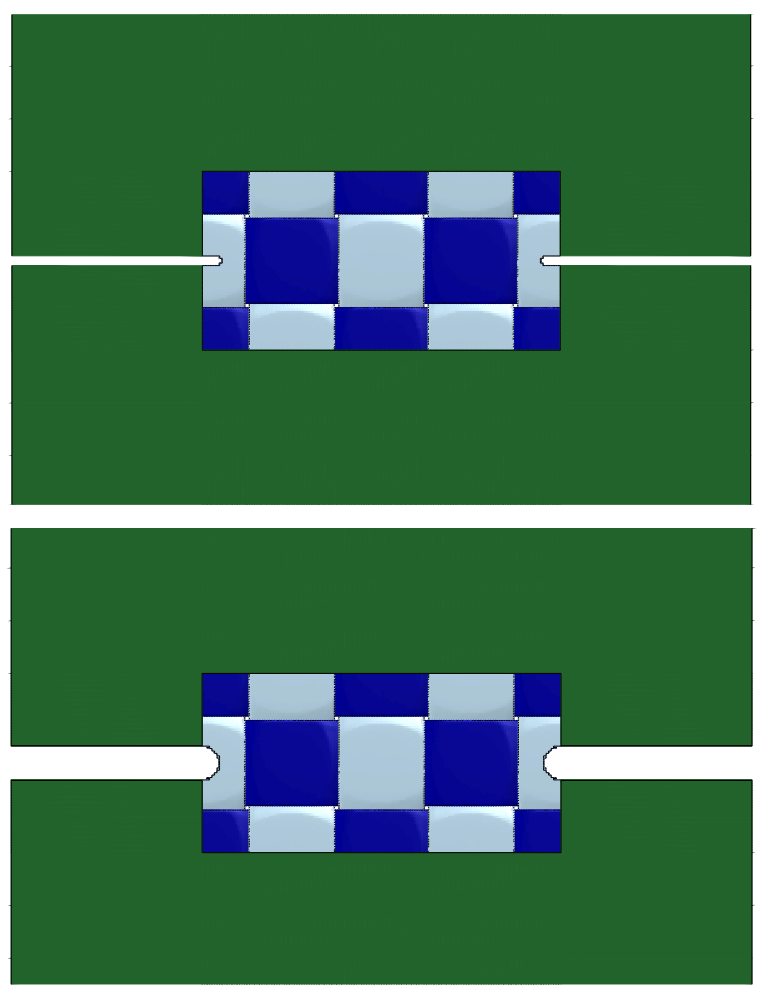

Figure 23 - Representation of the precrack tip within the EC, $r_{0}=0.15 \mathrm{~mm}$ (top) and $r_{0}=0.5 \mathrm{~mm}$ (bottom)

The epoxy matrix in the RUC was modelled using the elastic-plastic constitutive damage model proposed by Melro et al. [43], and was implemented as a VUMAT subroutine in Abaqus® [33]. The initial behaviour was linear elastic. A paraboloidal stress yield criterion was defined, as proposed by Tschoegl [44], and used together with a non-associative flow rule. A thermodynamically-consistent isotropic damage model was used, defined by a single damage variable, with a damage activation function, similar to the paraboloidal yield criterion, used to identify damage onset. However, this activation function uses the compressive and tensile strengths of the epoxy matrix, instead of the yield strengths and the concept of an effective stress tensor, i.e. the stress tensor calculated using the undamaged stiffness tensor. Mesh size dependency was avoided through the implementation of Bažant and Oh's crack band model [45], which uses the individual characteristic element length and the mode I fracture toughness of the epoxy, $G_{I C}^{m}$, to regularise the computed dissipated energy. It was implemented along with the definition of a damage evolution law [43]. For more details, the reader is referred to $[43,46]$.

The tows were modelled using a transversely isotropic intralaminar damage model developed by the Advanced Composites Research Group (ACRG) at Queen's University Belfast [10,47-49]. Faggiani and Falzon [47] combined Continuous Damage Mechanics (CDM) with the appropriate damage initiation criteria to produce a response model that is suitable for simulating impact damage on UD composite panels. For simulating the materials' crush response, i.e. a complex loading state with several damage interactions, additional features and/or modifications to the initial model were made to account for load reversal, stiffness degradation, capturing the in-situ effect [50], element objectivity [10], element deletion criteria [48] and non-linear shear behaviour [49]. For more details, the reader is referred to [10,47-49,51]. 
Since this comparative numerical analysis was only performed to assess the effect of precrack tip radius, the input values of the mechanical properties used to model each part of the FE model should have little influence in the simulations' outcome. Elastic and strength properties used to model the epoxy matrix and tows were assumed to be the ones obtained by Melro et al. [52], and are represented in Table 6 and Table 7 respectively. The elastic properties of the homogenised part are reported in Table 1 for Material 2.

Table 6 - Epoxy matrix material properties

\begin{tabular}{cc}
\hline Mechanical property & Epoxy matrix \\
\hline Elastic modulus & $E^{m}=3760 \mathrm{MPa}$ \\
Poisson's ratio & $v^{m}=0.39$ \\
Tensile strength & $X_{T}^{m}=93 \mathrm{MPa}$ \\
Compressive strength & $X_{C}^{m}=180 \mathrm{MPa}$ \\
Mode I fracture toughness & $G_{I C}^{m}=0.09 \mathrm{~kJ} / \mathrm{m}^{2}$ \\
\hline
\end{tabular}

Table 7 - Tow mechanical properties

\begin{tabular}{cc}
\hline Mechanical property & Tows \\
Elastic moduli & $E_{11}^{T}=138910 \mathrm{MPa} ; E_{22}^{T}=E_{33}^{T}=9380 \mathrm{MPa}$ \\
Poisson's ratios & $v_{12}^{T}=v_{13}^{T}=0.245 ; v_{23}^{T}=0.350$ \\
In-plane shear modulus & $G_{12}^{T}=5080 \mathrm{MPa}$ \\
Longitudinal tensile strength & $X_{T}^{T}=2057 \mathrm{MPa}$ \\
Longitudinal compressive strength & $X_{C}^{T}=1200 \mathrm{MPa}$ \\
Transverse tensile strength & $Y_{T}^{T}=68 \mathrm{MPa}$ \\
Transverse compressive strength & $Y_{C}^{T}=123 \mathrm{MPa}$ \\
Shear strengths & $S_{12}^{T}=S_{13}^{T}=48 \mathrm{MPa} ; S_{23}^{T}=39 \mathrm{MPa}$ \\
Mode I longitudinal intralaminar fracture toughness & $G_{I c}^{1 T}=101.5 \mathrm{~kJ} / \mathrm{m}^{2}[2]$ \\
Compressive longitudinal intralaminar fracture toughness & $G_{C C}^{1 T}=61 \mathrm{~kJ} / \mathrm{m}^{2}[20]$ \\
Mode I transverse intralaminar fracture toughness & $G_{I c}^{2 T}=0.2 \mathrm{~kJ} / \mathrm{m}^{2 \mathrm{a}}$ \\
Compressive transverse intralaminar fracture toughness & $G_{C c}^{2 T}=0.4 \mathrm{~kJ} / \mathrm{m}^{2 \mathrm{a}}$ \\
Mode II intralaminar fracture toughness & $G_{I I C}^{12 T}=G_{I I C}^{13 T}=G_{I I C}^{23 T}=0.4 \mathrm{~kJ} / \mathrm{m}^{2 \mathrm{a}}$ \\
\hline
\end{tabular}

${ }^{\text {a }}$ Estimated 
The numerical simulations were conducted using the FE solver Abaqus®/Explicit [33]. In order to avoid numerical errors due to excessive element distortion, damaged elements were removed throughout the simulations, through the following strategy [48]:

$$
\text { Delete element if }=\left\{\begin{array}{c}
d^{m}>0.99 \\
d_{11(T / C)}^{T}>0.99 \\
\operatorname{det} \boldsymbol{F} \leq 0.5 \vee \operatorname{det} \boldsymbol{F} \geq 3
\end{array}\right. \text {, }
$$

where $d^{m}$ is the matrix damage variable, $d_{11(T / C)}^{T}$ is the fibre-dominated longitudinal damage variable of the tows (for tension or compression), and $\operatorname{det} \boldsymbol{F}$ yields the ratio of an element's deformed volume, $V$, to its undeformed volume, $V_{0}: \operatorname{det} \boldsymbol{F}=V / V_{0}$.

\subsection{Numerical predictions and discussion}

Figure 24(a) shows quantitative numerical predictions of the nominal stress-displacement curves obtained for the two DENT models with differing precrack radii, with four indicated points (A-D), associated with the corresponding representations of Figure 24(b). The first three contour plots present the fibre tensile damage variable of the tows, while the fourth plot shows the deformed shape of the tows after the occurrence of numerical instabilities beyond peak load. For the sake of brevity, these contour plots only represent the tows within the EC of the model with $r_{0}=0.5 \mathrm{~mm}$. The ordinate value of the plot in Figure 24(a) represents the ratio of the nominal stress and the maximum nominal stress of the two curves. The four points identified in this curve represent: (A) no fibre damage in the tows; (B) initial crack propagation, identified from the deletion of some elements at the precrack tip; (C) peak load showing substantial fibre damage; (D) mode I unstable crack band propagation. Despite results showing a marginally higher peak nominal stress for the bigger precrack tip radius model $(<1 \%$ higher), the difference between the two models falls within the observed scatter of experimental results. Thus, the quantitative results of this study agree with the experimental observations. Figure 25 presents a qualitative comparison of the crack bands developed after peak load, for both models. The fracture surfaces through the tows are not representative of a pure slit, but a crack band, and are quite comparable between the two models. The initiation of such a crack band helps explain the precrack tip radius insensitivity observed in the unstable experiments of Material 1, even considering its small $c_{f}$. The assumption of a sharp crack tip at peak load would only justify the precrack tip radius insensitivity observed for Material 2.

Due to the qualitative and quantitative consistency observed both experimentally and numerically, the DECT and DENT specimens with the tested precrack radii can be used interchangeably in obtaining the fracture toughness of $2 \mathrm{D}$ woven composites. These results cannot be extended to other material configurations (such as UD), or for larger precrack radii, without further experimental justification. 


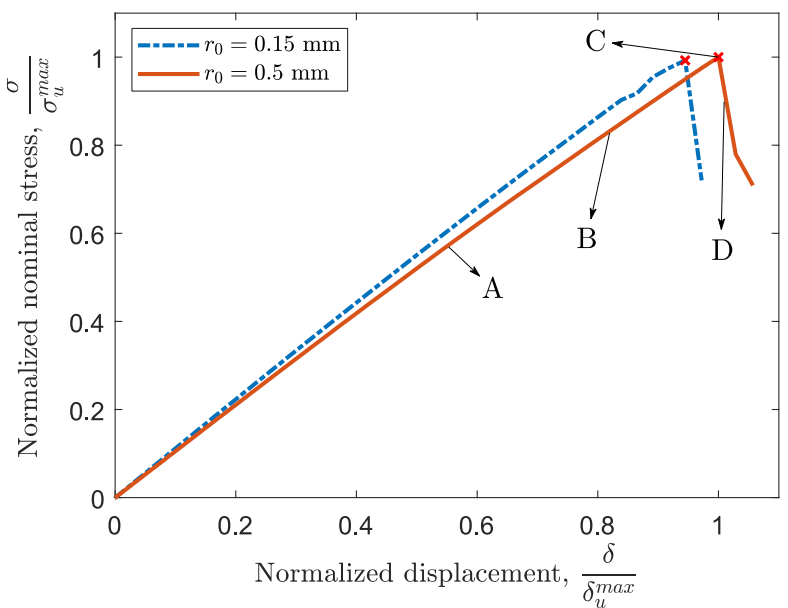

(a)
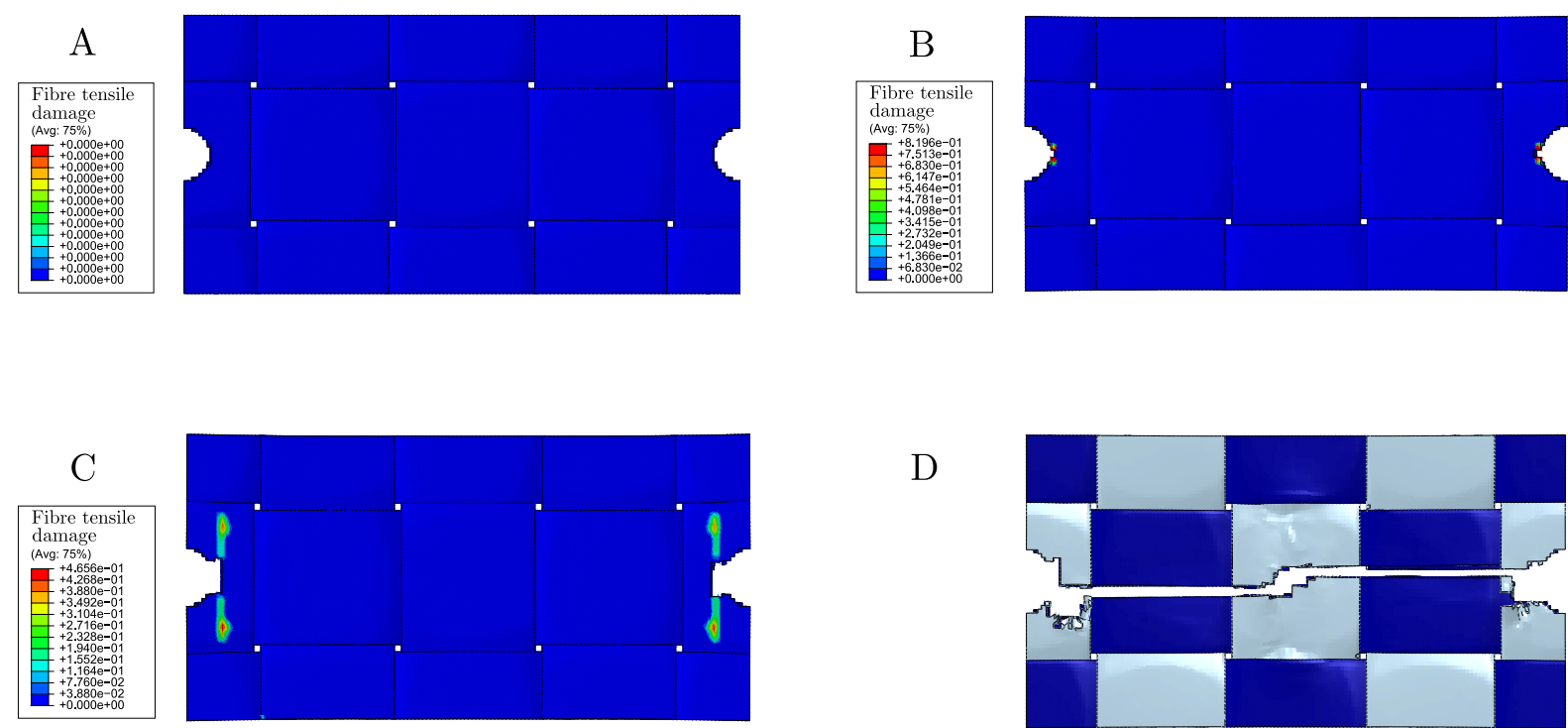

D

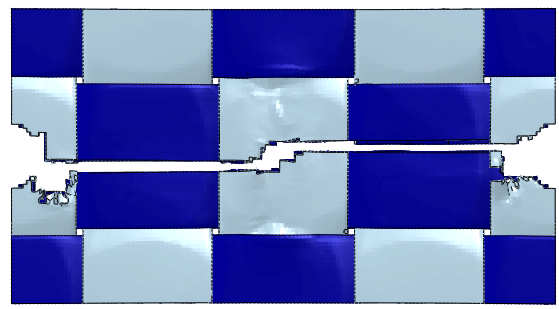

(b)

Figure 24 - Normalised nominal stress - displacement curves for the DENT FE models (a), and corresponding fibre tensile damage progression and final crack propagation through the EC volume (b) 

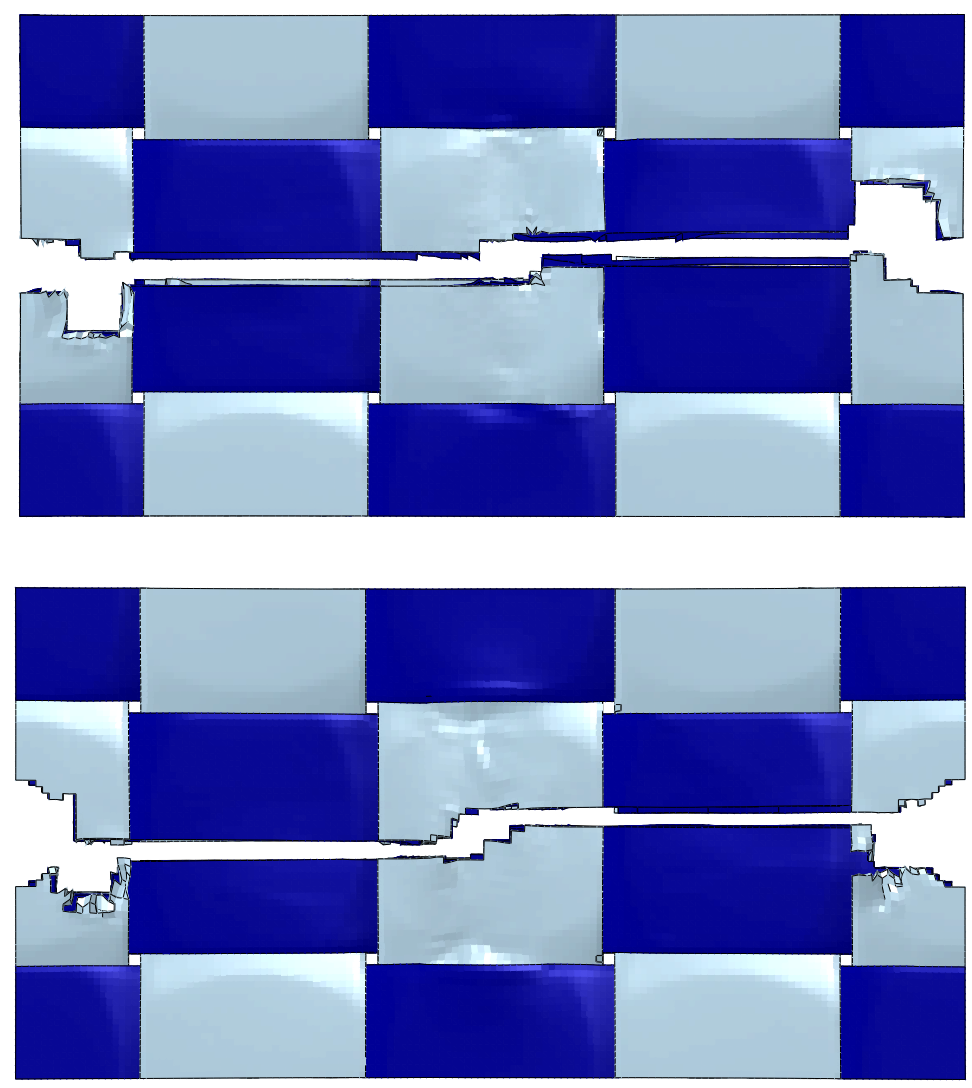

Figure 25 - Qualitative comparison of the crack bands developed after peak load, from the FE simulations with $r_{0}=0.15 \mathrm{~mm}$ (top) and $r_{0}=0.5 \mathrm{~mm}$ (bottom)

\section{Comparative discussion on stable and unstable crack propagation techniques}

The experimental results for both tested materials, from both stable and unstable techniques, converged to similar steady-state mode I intralaminar fracture toughness values. Since this $R_{S S}$ value, being the typical input value for most state-of-the-art composite intralaminar damage models, was the main objective of these experiments, the two methodologies can both be considered valid for such measurements.

With the aim of standardising such experiments, consideration was given to the material costs and total time (including preparation, testing and data reduction), their applicability to different composite material systems, objectivity, completeness of results, and eventual applicability to a wider spectrum of testing strain rates.

Comparatively, the cost of material for each test is quite insignificant, since relatively similar quantities are required. For manufacturing, both specimens are easy to cut using automated processes. However, by using small milled precracks, DENT specimens can eliminate the need of manual or particularly expensive manufacturing processes, while increasing the accuracy of the precrack lengths. Unstable testing used in combination with the size effect method only requires the peak load measurement, which is significantly simpler 
than setting up displacement and crack length measurement devices (LVDT, camera) for stable testing. The time required for data reduction can be significant for both methods. However, by using Eq. (12) for the geometric correction factor, and Eq. (14) for the energy release rate of 2D woven composites, the derivation of the size effect fitting and $R$-curve envelope can be automated, allowing the unstable method's data reduction to become significantly less time consuming. Since stable propagation methods require crack length increments to be noted from visual data, and correlated to respective load drops, the data reduction for such methods are harder to automate.

Multiple material systems with a range of fracture toughness values have been tested using both methodologies. However, toughened materials have necessitated several modifications for stable specimen geometries, such as the grooved CT used here for Material 2. The only variation in specimen geometry required by the unstable method would be to include larger specimen sizes for materials with significantly higher fracture toughness. The objectivity of stable techniques all rests on the crack length measurement, as already discussed in section 4.3 .

The results obtained from both techniques, although in agreement on $R_{S S}$, do not provide equal levels of information about the development and propagation of a material's fracture process zone (i.e. the $R$-curve). While the use of stiff and heavy grips could enable more data points to be derived from stable testing, the unstable technique derives the complete $R$-curve envelope while using standard tensile grips.

\section{Conclusions}

After comparing the experimental results obtained for both stable and unstable crack propagation techniques, and taking into account the qualitative and quantitative observations of the numerical studies for the precrack tip radius sensitivity of unstable specimens, the following conclusions are drawn:

- Unstable DENT specimens of 2D woven CFRP composites have been experimentally and numerically shown to possess a certain precrack tip radius insensitivity, within the tested radii $\left(0.15 \leq r_{0} \leq 0.5\right.$ $\mathrm{mm}$ ), as theoretically suggested by Catalanotti et al. [2]. This insensitivity is useful in simplifying the manufacturing process of precracks for such specimens. The use of automated machining will allow for an improved accuracy of the precrack length, reducing the experimental scatter in results.

- Both stable and unstable methodologies provide similar values for the steady-state mode I intralaminar fracture toughness of 2D woven composites. However, size effect testing of unstable geometries can provide a more comprehensive description of the development of a fracture process zone around a crack tip, by virtue of a size-independent $R$-curve, with the use of standard tensile experimental grips. Furthermore, the required geometric modifications necessary to delay undesired failure modes in CT 
specimens of toughened CFRP composites can act as a deterrent towards this specimen's eventual standardisation.

- The unstable crack propagation techniques exhibit numerous significant advantages over their stable counterparts. These include easier specimen manufacturing (automated precrack machining), simpler testing procedures (which only require a peak load), with a faster and more objective automated data reduction scheme. Furthermore, the data reduction scheme presented here has been further developed from that in [2], and is now applicable to most commercially available 2D woven composites without the need of any material orthotropy corrections, through the use of Trace Theory.

This study has built on and expanded the original work of Catalanotti et al. [2], to demonstrate the potential of the unstable size effect test method to be standardised for obtaining the mode I intralaminar fracture toughness of $2 \mathrm{D}$ woven composites. This experimental method can be extended to similarly obtain intralaminar fracture toughness values for other failure modes, over a range of strain rates. Further standardisation of such methods would enable the aerospace and automotive industries to adopt the state-of-the-art composite damage models currently being developed.

\section{Acknowledgements}

The authors gratefully acknowledge the financial support of the project ICONIC - Improvement of Crashworthiness of Composite Transportation Structures. ICONIC has received funding from the European Union's Horizon 2020 research and innovation programme under the Marie Skłodowska-Curie grant agreement No 721256. The content reflects only the author's view and the Agency is not responsible for any use that may be made of the information it contains.

\section{References}

[1] Laffan MJ, Pinho ST, Robinson P, McMillan AJ. Translaminar fracture toughness testing of composites: A review. Polym Test 2012;31:481-9. doi:10.1016/j.polymertesting.2012.01.002.

[2] Catalanotti G, Arteiro A, Hayati M, Camanho PP. Determination of the mode I crack resistance curve of polymer composites using the size-effect law. Eng Fract Mech 2014;118:49-65. doi:10.1016/j.engfracmech.2013.10.021.

[3] ASTM. D3039/D3039M-17 Standard Test Method for Tensile Properties of Polymer Matrix Composite Materials. 2017. doi:10.1520/D3039_D3039M-08.

[4] ASTM. D5528-13 Standard Test Method for Mode I Interlaminar Fracture Toughness of Unidirectional 
Fiber-Reinforced Polymer Matrix Composites 1 2015. doi:10.1520/D5528-13.2.

[5] Maimí P, Camanho PP, Mayugo JA, Dávila CG. A continuum damage model for composite laminates: Part I - Constitutive model. Mech Mater 2007;39:897-908. doi:10.1016/j.mechmat.2007.03.005.

[6] Maimí P, Camanho PP, Mayugo JA, Dávila CG. A continuum damage model for composite laminates: Part II - Computational implementation and validation. Mech Mater 2007;39:909-19. doi:10.1016/j.mechmat.2007.03.006.

[7] Falzon BG, Apruzzese P. Numerical analysis of intralaminar failure mechanisms in composite structures. Part I : FE implementation. Compos Struct 2011;93:1039-46. doi:10.1016/j.compstruct.2010.06.028.

[8] Falzon BG, Apruzzese P. Numerical analysis of intralaminar failure mechanisms in composite structures. Part II: Applications. Compos Struct 2011;93:1047-53. doi:10.1016/j.compstruct.2010.06.022.

[9] Camanho PP, Erçin GH, Catalanotti G, Mahdi S, Linde P. A finite fracture mechanics model for the prediction of the open-hole strength of composite laminates. Compos Part A Appl Sci Manuf 2012;43:1219-25. doi:10.1016/j.compositesa.2012.03.004.

[10] Tan W, Falzon BG, Chiu LNS, Price M. Predicting low velocity impact damage and Compression-AfterImpact (CAI) behaviour of composite laminates. Compos Part A 2015;71:212-26. doi:10.1016/j.compositesa.2015.01.025.

[11] Liu H, Falzon BG, Tan W. Experimental and numerical studies on the impact response of damagetolerant hybrid unidirectional/woven carbon-fibre reinforced composite laminates. Compos Part B Eng 2018;136:101-18. doi:10.1016/j.compositesb.2017.10.016.

[12] Salviato M, Chau VT, Li W, Bazant ZP, Cusatis G. Direct Testing of Gradual PostPeak Softening of Notched Specimens of Fiber Composites Stabilized by Enhanced Stiffness and Mass. J Appl Mech 2016;83:1-11. doi:10.1115/1.4034312.

[13] Donadon M V., Falzon BG, Iannucci L, Hodgkinson JM. Intralaminar toughness characterisation of unbalanced hybrid plain weave laminates. Compos Part A Appl Sci Manuf 2007;38:1597-611. doi:10.1016/j.compositesa.2006.12.003.

[14] Blanco N, Trias D, Pinho ST, Robinson P. Intralaminar fracture toughness characterisation of woven composite laminates. Part II: Experimental characterisation. Eng Fract Mech 2014;131:361-70. doi:10.1016/j.engfracmech.2014.08.011.

[15] Pinho ST, Robinson P, Iannucci L. Developing a four point bend specimen to measure the mode I intralaminar fracture toughness of unidirectional laminated composites. Compos Sci Technol 2009;69:1303-9. doi:10.1016/j.compscitech.2009.03.007.

[16] Li X, Hallett SR, Wisnom MR, Zobeiry N, Vaziri R, Poursartip A. Experimental study of damage propagation in Over-height Compact Tension tests. Compos Part A Appl Sci Manuf 2009;40:1891-9. doi:10.1016/j.compositesa.2009.08.017. 
[17] Bažant ZP, Planas J. Fracture and Size Effect in Concrete and other Quasibrittle Materials. CRC Press LCC, ISBN 0-8493-8284-Xº 1998:616. doi:084938284x.

[18] Salviato M, Kirane K, Esna Ashari S, Bažant ZP, Cusatis G. Experimental and numerical investigation of intra-laminar energy dissipation and size effect in two-dimensional textile composites. Compos Sci Technol 2016;135:67-75. doi:10.1016/j.compscitech.2016.08.021.

[19] Catalanotti G, Xavier J. Measurement of the mode II intralaminar fracture toughness and R-curve of polymer composites using a modified Iosipescu specimen and the size effect law. Eng Fract Mech 2015;138:202-14. doi:10.1016/j.engfracmech.2015.03.005.

[20] Catalanotti G, Xavier J, Camanho PP. Measurement of the compressive crack resistance curve of composites using the size effect law. Compos Part A Appl Sci Manuf 2014;56:300-7. doi:10.1016/j.compositesa.2013.10.017.

[21] Kuhn P, Catalanotti G, Xavier J, Ploeckl M, Koerber H. Determination of the crack resistance curve for intralaminar fiber tensile failure mode in polymer composites under high rate loading. Compos Struct 2018;204:276-87. doi:10.1016/j.compstruct.2018.07.039.

[22] Kuhn P, Catalanotti G, Xavier J, Camanho PP, Koerber H. Fracture toughness and crack resistance curves for fiber compressive failure mode in polymer composites under high rate loading. Compos Struct 2017;182:1-45. doi:10.1016/j.compstruct.2017.09.040.

[23] Marín L, González E V., Maimí P, Trias D, Camanho PP. Hygrothermal effects on the translaminar fracture toughness of cross-ply carbon/epoxy laminates: Failure mechanisms. Compos Sci Technol 2016;122:130-9. doi:10.1016/j.compscitech.2015.10.020.

[24] Laffan MJ, Pinho ST, Robinson P, McMillan AJ. Translaminar fracture toughness: The critical notch tip radius of $0^{\circ}$ plies in CFRP. Compos Sci Technol 2011;72:97-102. doi:10.1016/j.compscitech.2011.10.006.

[25] Camanho PP, Catalanotti G. On the relation between the mode I fracture toughness of a composite laminate and that of a $0^{\circ}$ ply: Analytical model and experimental validation. Eng Fract Mech 2011;78:2535-46. doi:10.1016/j.engfracmech.2011.06.013.

[26] Laffan MJ, Pinho ST, Robinson P, Iannucci L. Measurement of the in situ ply fracture toughness associated with mode I fibre tensile failure in FRP. Part I: Data reduction. Compos Sci Technol 2010;70:606-13. doi:10.1016/j.compscitech.2009.12.016.

[27] Suo Z, Bao G, Fan B, Wang TC. Orthotropy rescaling and implications for fracture in composites. Int J Solids Struct 1991;28:235-48. doi:10.1016/0020-7683(91)90208-W.

[28] Whitney JM, Browning CE, Hoogsteden W. A double cantilever beam test for characterizing Mode I delamination of composite materials. J Reinf Plast Compos 1982;1:297-313.

[29] Catalanotti G, Camanho PP, Xavier J, Dávila CG, Marques AT. Measurement of resistance curves in the 
longitudinal failure of composites using digital image correlation. Compos Sci Technol 2010;70:198693. doi:10.1016/j.compscitech.2010.07.022.

[30] Ortega A, Maimí P, González E V., Ripoll L. Compact tension specimen for orthotropic materials. Compos Part A Appl Sci Manuf 2014;63:85-93. doi:10.1016/j.compositesa.2014.04.012.

[31] Dávila CG, Rose CA, Camanho PP. A procedure for superposing linear cohesive laws to represent multiple damage mechanisms in the fracture of composites. Int $\mathbf{J}$ Fract 2009;158:211-23. doi:10.1007/s10704-009-9366-z.

[32] Tada H, Paris PC, Irwin GR. The stress analysis of cracks handbook 2000:58. doi:10.1115/1.801535.

[33] ABAQUS Version 2017 Documentation. Dassault Systèmes 2017.

[34] Krueger R. Virtual crack closure technique: History, approach, and applications. vol. 2002-10. 2002.

[35] Kuraishi A, Tsai SW, Liu KKS. A progressive quadratic failure criterion, part B. Fail Criteria FibreReinforced-Polymer Compos 2004;62:903-21. doi:10.1016/B978-008044475-8/50031-7.

[36] Hooper E, Bonitati A, Man M, Tanoto V, Lian E. TCAC 12k HTS40 SFP OSI / TC250 42 \% Fabric Prepreg Material Property Data Report. 2016.

[37] Hooper E, Tanoto V, Lovingfoss R, Lian E. Solvay Cytec Cycom EP 2202 T650 3K-PW Fabric 38\%RC Qualification Material Property Data Report. 2017.

[38] Hooper E, Man M, Lovingfoss R, Ng Y, Lian E. Cytec Cycom 5320-1 T650 3K-PW Fabric Qualification Material Property Data Report. 2015.

[39] Hooper E, Marlett K, Ng Y, Tomblin J. Hexcel 8552S AS4 Plain Weave Fabric Prepeg 193 gsm \& 38\% RC Qualification Material Property Data Report. 2011.

[40] Gurit. SE 84LV Low Temperature Cure Epoxy Prepreg- General Datasheet. 2017.

[41] ASTM. D7078/D7078M -12 Standard Test Method for Shear Properties of Composite Materials by VNotched Rail Shear Method. 2012. doi:10.1520/D7078.

[42] Liu H, Falzon BG, Catalanotti G, Tan W. An experimental method to determine the intralaminar fracture toughness of high-strength carbon-fibre reinforced composite aerostructures. Aeronaut J 2018:1-19. doi:10.1017/aer.2018.78.

[43] Melro AR, Camanho PP, Andrade Pires FM, Pinho ST. Micromechanical analysis of polymer composites reinforced by unidirectional fibres: Part I-Constitutive modelling. Int J Solids Struct 2013;50:1897-905. doi:10.1016/j.ijsolstr.2013.02.009.

[44] Tschoegl NW. Failure surfaces in principal stress space. J Polym Sci Part C Polym Symp 1971;32:23967.

[45] Bažant ZP, Oh B. Crack band theory for fracture of concrete. Mater Struct 1983;16:155-77.

[46] Melro AR, Camanho PP, Andrade Pires FM, Pinho ST. Micromechanical analysis of polymer 
composites reinforced by unidirectional fibres: Part II-Micromechanical analyses. Int J Solids Struct 2013;50:1906-15. doi:10.1016/j.ijsolstr.2013.02.007.

[47] Faggiani A, Falzon BG. Predicting low-velocity impact damage on a stiffened composite panel. Compos Part A Appl Sci Manuf 2010;41:737-49. doi:10.1016/j.compositesa.2010.02.005.

[48] Tan W, Falzon BG, Price M. Predicting the crushing behaviour of composite material using high-fidelity finite element modelling. Int J Crashworthiness 2015;20:60-77. doi:10.1080/13588265.2014.972122.

[49] Tan W, Falzon BG. Modelling the crush behaviour of thermoplastic composites. Compos Sci Technol 2016;134:57-71. doi:10.1016/j.compscitech.2016.07.015.

[50] Catalanotti G, Camanho PP, Marques AT. Three-dimensional failure criteria for fiber-reinforced laminates. Compos Struct 2013;95:63-79. doi:10.1016/j.compstruct.2012.07.016.

[51] Falzon BG, Liu H, Tan W. Comment on "A tensorial based progressive damage model for fibre reinforced polymers.” Compos Struct 2017;176:877-82. doi:10.1016/j.compstruct.2017.06.011.

[52] Melro AR, Camanho PP, Andrade Pires FM, Pinho ST. Numerical simulation of the non-linear deformation of 5-harness satin weaves. Comput Mater Sci 2012;61:116-26. doi:10.1016/j.commatsci.2012.04.010. 